BNL-101089-2012-IR

\title{
Self-decomposable Fibrous Bridging Additives for Temporary Cementitious Fracture Sealers in EGS Wells
}

\author{
T. Sugama ${ }^{1}$, T. Pyatina' ${ }^{1}$, S. Gill ${ }^{1}$, K. Kisslinger ${ }^{1}$, \\ B. Iverson ${ }^{2}$, D. Bour ${ }^{3}$ \\ ${ }^{1}$ Brookhaven National Laboratory, Upton, NY 11973 USA \\ ${ }^{2}$ Halliburton Cementing Applied Science and Processes, Houston, TX USA \\ ${ }^{3}$ Geodynamic Limited, Milton, Australia
}

November 2012

\begin{abstract}
Sustainable Energy Technologies Department/Energy Conversion Group Brookhaven National Laboratory
\end{abstract}

\section{U.S. Department of Energy DOE Office of Energy Efficiency and Renewable Energy}

\footnotetext{
Notice: This manuscript has been authored by employees of Brookhaven Science Associates, LLC under Contract No. DE-AC02-98CH10886 with the U.S. Department of Energy. The publisher by accepting the manuscript for publication acknowledges that the United States Government retains a non-exclusive, paid-up, irrevocable, world-wide license to publish or reproduce the published form of this manuscript, or allow others to do so, for United States Government purposes.
} 


\section{DISCLAIMER}

This report was prepared as an account of work sponsored by an agency of the United States Government. Neither the United States Government nor any agency thereof, nor any of their employees, nor any of their contractors, subcontractors, or their employees, makes any warranty, express or implied, or assumes any legal liability or responsibility for the accuracy, completeness, or any third party's use or the results of such use of any information, apparatus, product, or process disclosed, or represents that its use would not infringe privately owned rights. Reference herein to any specific commercial product, process, or service by trade name, trademark, manufacturer, or otherwise, does not necessarily constitute or imply its endorsement, recommendation, or favoring by the United States Government or any agency thereof or its contractors or subcontractors. The views and opinions of authors expressed herein do not necessarily state or reflect those of the United States Government or any agency thereof. 


\begin{abstract}
This study evaluates compatibility of a self-degradable temporary fracture sealer with the drilling mud and plugging and self-degrading performance of different fibers to be used in combination with the sealer. The sodium silicate-activated slag/Class C fly ash (SSASC) cementitious sealer must plug fractures at $85^{\circ} \mathrm{C}$ to allow continuous well drilling and it must degrade and leave the fractures open for water at later times when exposed to temperatures above $200^{\circ} \mathrm{C}$.

The sealer showed good compatibility with the mud. Even the blend of 80/20 vol.\% of sealer/mud reached a compressive strength of more than 2000 psi set as one of the material criteria, mostly due to the additional activation of the slag and Class C fly ash by the alkaline ingredient present in the drilling fluid. In contrast, the drilling fluid was detrimental to the compressive strength development in conventional Class $\mathrm{G}$ well cement, so that it failed to meet this criterion.

Among several organic fibers tested both polyvinyl alcohol (PVA)-and nylon-based fibers showed adequate plugging of the sealer in slot nozzles of 1 -in. wide $x$ 6-in. long $\mathrm{x}$ 0.08 in. and 0.24 in. high under pressures up to 700 psi. PVA fibers displayed better compressive toughness and self-degrading properties than nylon. The compressive toughness of sealers made by adding $1.0 \mathrm{wt} \% 6 \mathrm{~mm}$-length PVA and $0.5 \mathrm{wt} \% 19 \mathrm{~mm}-$ length PVA was 9.5-fold higher than that of a non-bridged sealer. One factor governing the development of such high toughness was an excellent adherence of PVA to the SSASC cement. The alkali-catalyzed self-decomposition of PVA at $200^{\circ} \mathrm{C}$ led to the morphological transformation of the material from a fibrous structure to a microscale flake-like structure that helped the desirable conversion of the sealer into small fragments. In contrast, nylon's decomposition provided a reticular network structure in the self-degraded sealer resulting in bigger fragments compared against the sealer with PVA. The PVA fiber has a high potential as a self-decomposable bridging additive in the SSASC cement sealer.
\end{abstract}




\section{Introduction}

In our previous works aimed at developing the self-degrading temporary cementitious sealers in Enhanced Geothermal Systems (EGSs), our focus centered on the following four major tasks: First task was to formulate alkali-activated cementitious binders consisting of the sodium silicate as alkali activator and industrial by-products such as granulated blast-furnace slag (GBFS), and Class C or F fly ashes, as cement-forming materials; second task was to identify self-degradation promoting additives suitable for these cementitious sealers; third aim was to understand the self-degrading mechanisms of the formulated temporary sealer; and, fourth was to design a sealer possessing the volumetric expansion properties in a hydrothermal environment.

We formulated two candidate sealing systems in this first task. One system was composed of $20 \mathrm{wt} \%$ slag and $80 \mathrm{wt} \%$ Class C fly ash, and the other system consisted of $40 \mathrm{wt} \%$ slag and $60 \mathrm{wt} \%$ Class F fly ash. The sodium silicate activator of up to $6 \mathrm{wt} \%$ by total weight of slag/Class $\mathrm{C}$ or $\mathrm{F}$ fly ash mixtures was added to these systems to assemble a cementitious structure and to develop a compressive strength of more than $2000 \mathrm{psi}$ $[1,2]$ after autoclaving at temperatures of $\geq 85^{\circ} \mathrm{C}$. In the second task, considerable attention was paid to assessing the ability of sodium carboxymethyl celluloses (CMCs) to promote the sealer's self-degradation under two possible EGS well conditions: where the sealer was in a hot wet environment facing an inlet of fracture or where the sealer was exposed to a hot dry condition at the fracture's outlet. Accordingly, we proposed in task 3 a hypothetical self-degradation mechanism encompassing two vital factors governing the magnitude of self-degradation of the sealers: One factor was the amount of free $\mathrm{NaOH}$ liberated from the sodium silicate activator dissolved in water; and, the other was the emission of volatile $\mathrm{CO}_{2}$ gas and acetic acid vapor from thermally decomposed $\mathrm{CMC}$ $[3,4]$. The expansion of the sealer highlighted in task 4 was one of the desirable properties; namely, it should adequately plug the fractures without its dislodgement from fractures when drilling operation is resumed. We identified hard-burned magnesium oxide $(\mathrm{MgO})$ as an alternative expansive additive that improved the sealer's plugging

performance. The in-situ growth of brucite crystals formed by the hydrothermal hydration of $\mathrm{MgO}$ was responsible for such expansion of the sealer [5].

Using the temporary cementitious sealing systems described above, our focus then shifted to accomplishing the following three new tasks: The first task was to investigate the compatibility of the sealer slurry with a drilling fluid; the second one was to develop fibrous bridging additives, ensuring that the sealer slurry adequately plugs fractures with different sizes; and, the final task was to evaluate the self-decomposing performance of the fiber-bridged sealer in the fractures.

To use the sealer for curing lost circulation during the drilling operations it must be compatible with the drilling fluid. This mostly means that the sealer contaminated with the drilling mud should remain pumpable and keep desirable mechanical properties after setting. Since the common well temperature during drilling operations in geothermal wells is around $85^{\circ} \mathrm{C}$, we studied setting behavior of the sealer-mud blends (up to $20 \mathrm{vol} . \%$ of the mud) at that temperature. 
In the last two tasks, the ideal fibrous bridging additives must not only improve sealer's plugging performance at a low temperature of $85^{\circ} \mathrm{C}$, but also self-decompose when the self-degradation of cementitious sealing matrix begins at $\geq 200^{\circ} \mathrm{C}$. Since the $\mathrm{pH}$ of the sealer slurry is $>13$ our particular interest was in fibers' behavior in highly alkaline solutions at $85^{\circ} \mathrm{C}$ and their susceptibility to decomposition at $200^{\circ} \mathrm{C}$.

As already is known, the organic fibers such as acrylic, nylon, polyethylene (PE), and polyvinyl alcohol (PVA) have great potential as reinforcements for improving the tensile strength, elastic modulus, and toughness of cement and concrete because of their excellent properties of dispersion in cement slurry, good adherence to cement matrix, and moderate resistance to the alkaline pore solution ( $\mathrm{pH} 12-13)$ in cement. Our particular attention was paid to the high-temperature alkali resistance of the fibers, which depends on their molecular structure. For instance, when the acrylic-based fiber is exposed to alkaline environment at $80^{\circ} \mathrm{C}$, the ester group within the fiber's molecular structure is converted into the carboxylate group when the fiber undergoes hydrolysis [6]. In contrast, PVA fiber in cement composite at $100^{\circ} \mathrm{C}$ confers increased strain capacity on cement, corresponding to a good interfacial bonding between the fiber and cement and to an improved ductility of cement. Increasing the temperature to $150^{\circ} \mathrm{C}$ causes a loss in ductility of this composite because of the fiber's degradation [7]. Organic fibrous materials have been used effectively to cure circulation losses during cementing and drilling operations because of their ability to create a mat-like structure decreasing the poor size at the formation [8].

We investigated potential of four organic fibers, acrylic, nylon, polyethylene (PE), and polyvinyl alcohol (PVA), as bridging additives, to resolve the lost-circulation problem at $85^{\circ} \mathrm{C}$ with further self-decomposition when well temperature rises to $200^{\circ} \mathrm{C}$.

To complete the outlined tasks we obtained the following information: The changes in hydrolysis/hydration-related energy of the drilling-mud contaminated sealer slurry as a function of the amount of the drilling fluid at $85^{\circ} \mathrm{C}$; the compressive strength of drilling fluid-contaminated sealer cured at $85^{\circ} \mathrm{C}$; the thermal decomposition behaviors of the cement's pore solution-treated and non-treated fibers; the ability of fibers to plug slots of 1-in. wide x 6-in. long x 0.08 in. or $\times 0.25$ in. high under pressures up to $700 \mathrm{psi}$; the self-degrading performance of $200^{\circ} \mathrm{C}$-heated fiber-containing sealer composite after contact with water; the mechanical behaviors of fiber-bridged sealer composites; and, the exploration of microstructures developed in self-decomposed fibers and self-degraded fiber-bridged composites.

\section{Experimental procedure}

\subsection{Materials}

Two industrial by-products possessing pozzolanic properties were used as the hydraulic pozzolana cement: One was granulated blast-furnace slag under the trade name "New Cem"; the other was Class C fly ash. The slag was supplied by Lafarge North America, 
and the fly ash was obtained from Boral Material Technologies, Inc. Their chemical compositions detected by micro energy-dispersive X-ray spectrometer ( $\mu$ EDX) were as follows: Slag; $38.5 \mathrm{wt} \% \mathrm{CaO}, 35.2 \mathrm{wt} \% \mathrm{SiO}_{2}, 12.6 \mathrm{wt} \% \mathrm{Al}_{2} \mathrm{O}_{3}, 10.6 \mathrm{wt} \% \mathrm{MgO}, 1.1 \mathrm{wt} \%$ $\mathrm{Fe}_{2} \mathrm{O}_{3}$, and 0.4 wt $\% \mathrm{TiO}_{2}$; and, Class $\mathrm{C}$ fly ash; 30.2 wt\% $\mathrm{CaO}, 31.9$ wt\% $\mathrm{SiO}_{2}, 21.7$ wt\% $\mathrm{Al}_{2} \mathrm{O}_{3}, 4.6 \mathrm{wt} \% \mathrm{MgO}, 6.1 \mathrm{wt} \% \mathrm{Fe}_{2} \mathrm{O}_{3}, 1.7 \mathrm{wt} \% \mathrm{Na}_{2} \mathrm{O}, 0.7 \mathrm{wt} \% \mathrm{~K}_{2} \mathrm{O}_{3}$, and $3.1 \mathrm{wt} \% \mathrm{SO}_{3}$. A sodium silicate granular powder under the trade name "Metso Beads 2048," supplied by The PQ Corporation, was used as the alkali activator of these pozzolana cements; its chemical composition was $50.5 \mathrm{wt} \% \mathrm{Na}_{2} \mathrm{O}$ and $46.6 \mathrm{wt} \% \mathrm{SiO}_{2}$. Sodium carboxymethyl cellulose (CMC) under the production name "Walcocel CRT 30000 PA," supplied by Dow Chemical Corp, was used as a self-degradation promoter of cementitious sealer. The formula of the dry pozzolana cements employed in this test had a slag/Class C fly ash ratio of 20/80 by weight. Sodium silicate powder served as alkali activator was added at 6 $\%$ by total weight of pozzolana cement to prepare the dry blend of the cementitious material. Further, 1.2\% CMC by the total weight of pozzolana cement was incorporated into this dry mix. Class $\mathrm{G}$ well cement containing quartz flour $(35 \mathrm{wt} \%)$ was used as a control.

We prepared a typical water-based drilling fluid consisting of $0.27 \%$ caustic soda, $0.53 \%$ Lignosulfonic acid, $0.27 \%$ polyanionic cellulose, $0.27 \%$ xanthan gum, $1.5 \%$ barite, $5.3 \%$ bentonite gel, and $91.9 \%$ water for application in geothermal wells [9] to evaluate sealer's compatibility with the drilling fluid.

Four organic fibrous materials, acrylic, nylon, polyethylene (PE), and polyvinyl alcohol (PVA), were tested as bridging additives, which may resolve lost-circulation problems at $85^{\circ} \mathrm{C}$, and trigger their own self-degradation later on when the well temperature is raised to $200^{\circ} \mathrm{C}$. The nylon- and PVA-based fibers were obtained from Nycon Corporation, while Mini Fiber, Inc. supplied the acrylic- and PE-based fibers. We used the fibers of socalled short- and long-lengths. For the short fibers, their sizes were as follows: Nylon (18 $\mu \mathrm{m}$ diam. x $6 \mathrm{~mm}$ long under the trade name Multimesh); PVA (24 $\mu \mathrm{m}$ diam. x $6 \mathrm{~mm}$ long under the trade name PVA RMS702); and, PE (29 $\mu \mathrm{m}$ diam. x $6 \mathrm{~mm}$ long under the trade name Low-Melt LLDPE). The sizes of long fibers were the following: Acrylic (72 $\mu \mathrm{m}$ diam. x $25 \mathrm{~mm}$ long); nylon (38 $\mu \mathrm{m}$ diam. x $19 \mathrm{~mm}$ long under the trade name Multimesh); and, PVA (200 $\mu \mathrm{m}$ diam. x $19 \mathrm{~mm}$ long under the trade name PVA RFS400). These fibers were incorporated into the dry blend of cementitious materials at up to 4 wt.\% concentration.

In preparing the cementitious sealers, an appropriate amount of water was added to the dry cement mixture with and without fibrous bridging additives at room temperature. Then, some sealer slurries were mixed with drilling fluid. The slurries were left at room temperature in air until they solidified. Afterward, all set cements were exposed in an autoclave at $85^{\circ} \mathrm{C}$ for 24 hours under pressure of 1000 psi to prepare a solid sealer under the assumption that the drilling operation is performed at this well temperature. Subsequently, some of $85^{\circ} \mathrm{C}$ - autoclaved sealers were used for determining their compressive strength and compressive toughness, and the rest of autoclave sealers were heated for 24 hours in an oven at $200^{\circ} \mathrm{C}$. Then the heated sealers were used to visually observe their self-degrading performance after immersing them in water. 
To investigate effect of alkaline cement slurry on organic fibers at $85^{\circ}$ and at $200^{\circ} \mathrm{C}$, the pore solution of cement was extracted from sodium silicate-activated 20/80 slag/Class C fly ash ratio slurry by centrifuging it at $6000 \mathrm{rpm}$ for $10 \mathrm{~min}$. The $\mathrm{pH}$ of extracted pore solution was 13.7. The samples were prepared in the following manner: First, $0.5 \mathrm{~g}$ fiber was immersed in a $8 \mathrm{~g}$ pore solution at room temperature; second, a pore solution-wetted fiber was exposed in autoclave for 24 hours at $85^{\circ}$ and at $200^{\circ} \mathrm{C}$.

\subsection{Measurements}

TAM Air Isothermal Microcalorimetry was employed to obtain the initial setting time and to determine the maximum heat flow evolved by the hydrolysis-hydration reactions of cementitious sealer slurry with and without drilling fluid at an isothermal temperature of $85^{\circ} \mathrm{C}$. The changes in compressive strength for $85^{\circ} \mathrm{C}-24 \mathrm{hr}$-autoclaved sealers as a function of drilling fluid's content were obtained using Instron Model 5967. The cylindrical specimens (16 $\mathrm{mm}$ diameter by $35 \mathrm{~mm}$ long) were used for determining these properties, computed by Instron software. We investigated the thermal decompositionrelated properties of non-treated- and pore solution treated-fibers using Thermo Gravimetric Analysis (TGA) at the heating rate of $20^{\circ} \mathrm{C} / \mathrm{min}$ in a $\mathrm{N}_{2}$ flow. The HighResolution Scanning Electron Microscopy (HR-SEM) was used to investigate the morphologies of decomposed fibers after exposure to an alkaline pore solution at $200^{\circ} \mathrm{C}$ and to explore the microstructure developed in self-degraded fiber-bridging sealers.

Figure 1 shows small-scale slot test apparatus consisting of 3.8 in. diam. x 11.6 in. high steel container attached to 1 -in. wide x 6-in. long x 0.08 or 0.24 in. high slot nozzle. This apparatus was designed to sustain a maximum pressure of $1000 \mathrm{psi}$ and to screen bridging additives. The slot test was performed in the following manner: First, $1200 \mathrm{~g}$ sealer slurry containing an appropriate amount of fibrous bridging additives was poured into the inlet valve-closed container; second, the container was sealed with a pressure-controlling cap; third, 20 psi as the first loading pressure was imposed upon the slurry for a 3 min, followed by opening the inlet valve; fourth, if some slurry was lost by filtrating it through a 6-in. long slot, we measured the total amount of filtrated slurry and detailed the filtration loss of sealer; fifth, if there was no further loss of slurry after 3 min under pressure, then the pressure was increased to 50 psi as the second loading 


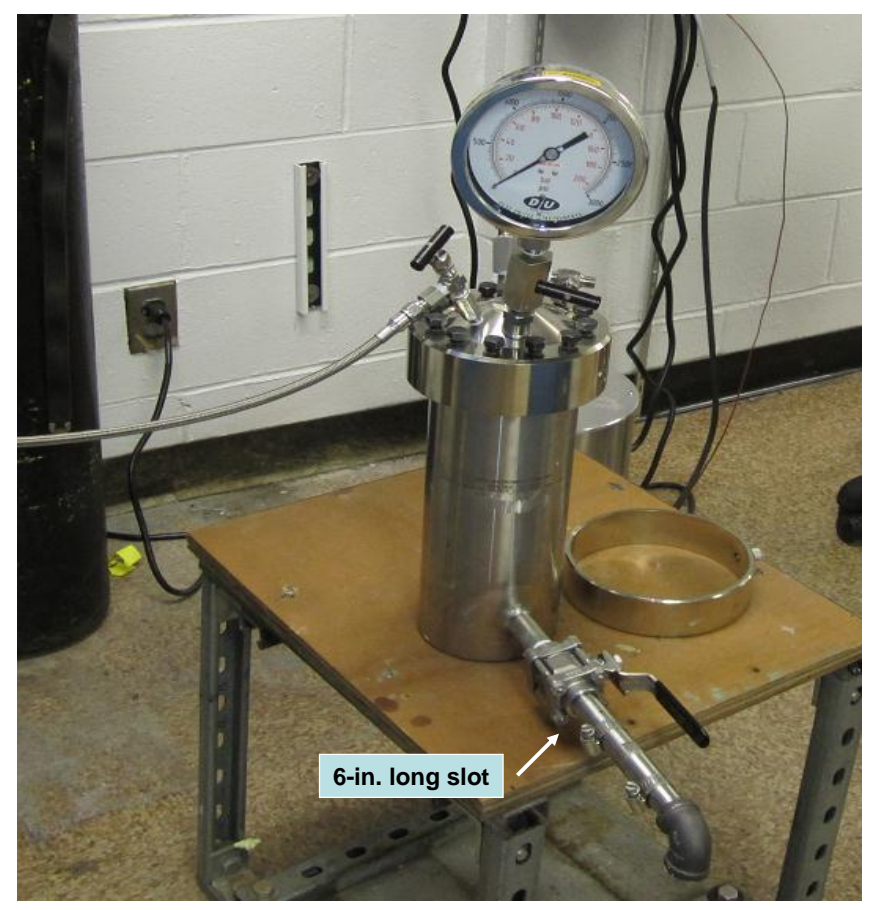

Figure 1. Small-scale slot apparatus used in screening a potential bridging additive.

pressure and maintained for $3 \mathrm{~min}$; sixth, the same testing procedure was repeated at 100, 200-, 500-, and 700-psi pressure; seventh, if the whole slurry was lost at a certain pressure, we denoted it as $100 \%$ filtration loss of sealer in terms of the sealer's failure; and if no loss under the pressures up to 700 psi was observed, we reported a zero filtration loss of sealer in terms of a potential bridging additive.

\section{Results and Discussion}

\subsection{Compatibility of sealer with drilling fluid}

The drilling fluid was blended directly with the sodium silicate-activated slag/Class C fly ash (SSASC) cementitious sealer slurry at $25^{\circ} \mathrm{C}$ to make the samples with the ratios of $100 / 0,95 / 5,90 / 10,85 / 15$, and 80/20 sealer/drilling fluid by volume. Then, these blended and non-blended sealer slurries were used to measure their hydrolysis/hydration reactiondeduced energy at isothermal temperature of $85^{\circ} \mathrm{C}$. Further, these blended slurries were autoclaved at $85^{\circ} \mathrm{C}$ for 24 hours to cure the sealers, followed by determining the compressive strength of cured samples.

\subsubsection{Hydrolysis-hydration behaviors}


To evaluate effect of the drilling-mud contamination on the hydrolysis-hydration behavior of SSASC cement slurries we obtained two factors from the heat flow-time relation curves: One was the maximum heat flow (MHF), $\mathrm{mW} / \mathrm{g}$, evolved during the hydrolysis and hydration a slurry containing drilling fluid; the other was the elapsed time to reach MHF after slurry-containing ampoules were placed in a calorimeter.

Figure 2 depicts the microcalorimeter curves in the elapsed times up to $12 \mathrm{hr} 30 \mathrm{~min}$ for $5-, 10-$, and 20 vol.\% drilling fluid-contaminated and non-contaminated SSASC slurries. For the control slurry noted as $0 \%$ drilling fluid, the peak of heat flow-time curve and the elapsed time consumed to reach its peak was $12.2 \mathrm{~mW} / \mathrm{g}$ and $1 \mathrm{hr} 48 \mathrm{~min}$, respectively, at $85^{\circ} \mathrm{C}$. The peak of this curve represents the MHF energy evolved by the combination of the hydrolysis and hydration reactions of slag and Class $\mathrm{C}$ fly ash. We assumed that the hydrolysis of these reactants was initiated by the

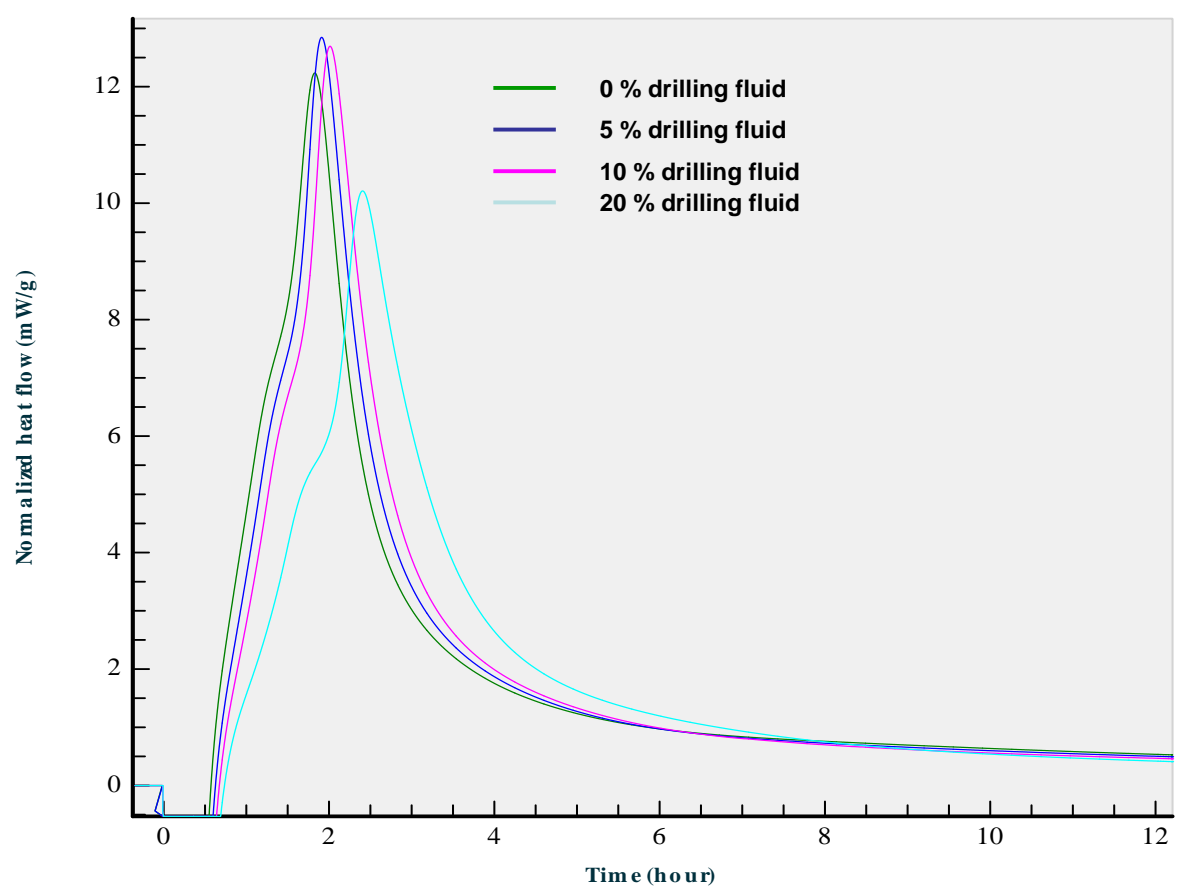

Figure 2. Microcalorimetric curves for 0, 5, 10, and 20 vol.\% drilling fluid-incorporated sealer slurries at $85^{\circ} \mathrm{C}$.

alkali activation of sodium silicate-derived $\mathrm{NaOH}$, thereby dissociating the cement and forming ionic hydrolysates. Concurrently, the hydration reactions of the ionic hydrolysates led to the conversion of slurry into a solid cementitious structure. After adding a 5 vo.\% drilling fluid to the slurry, two major features of this curve differed from that of the control: First, the MHF energy increased by 5 vol. $\%$ to $12.8 \mathrm{~mW} / \mathrm{g}$; second, there was a 7 min extension of elapsed time at the MHF to $1 \mathrm{hr} 55 \mathrm{~min}$. A possible reason for the former difference is that the chemical ingredients in drilling fluid, in particular, caustic soda might act as a strong alkaline agent, promoting the hydrolysis-hydration reactions of the slag and Class $\mathrm{C}$ fly ash. The latter one may be due to the weakly retarding effect of the mud on the cement set and incorporation of additional water with the drilling fluid. Increasing the content of drilling fluid to 10 and $20 \mathrm{vol} . \%$ engendered a 
further extended elapsed time to the MHF and a decline of MHF energy, compared with that of $5 \mathrm{vol} . \%$. Thus, the content of the free water present in a $5 \mathrm{vol} . \%$ drilling fluid seemingly does not cause any changes in the hydrolysis/hydration reaction-derived energy.

Figure 3 illustrates the heat flow-time relation for $0,5,10$, and 20 vol.\% drilling fluidmodified Class $\mathrm{G}$ well cement slurries. The unmodified Class $\mathrm{G}$ slurry generated the MHF of $25.1 \mathrm{~mW} / \mathrm{g}$ during its hydrolysis-hydration reaction, and the elapsed time to reach the MHF was $2 \mathrm{hrs} 21 \mathrm{~min}$. The value of MHF declined with an increasing amount of drilling fluid, while the elapsed time at MHF extended from $141 \mathrm{~min}$ for unmodified slurry to $735 \mathrm{~min}$ for $20 \mathrm{vol} . \%$ drilling fluid-modified one.

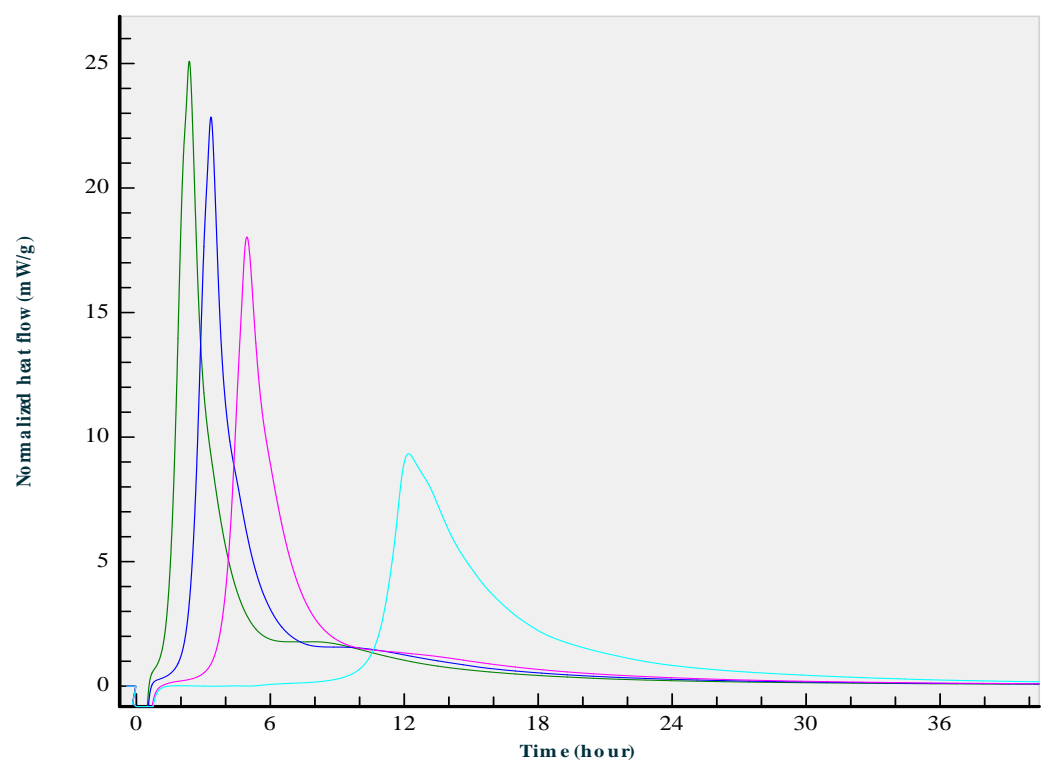

Figure 3. Heat flow-time relation curves for Class $\mathrm{G}$ well cement slurries modified with $0,5,10$, and 20 vol. $\%$ drilling fluid.

Figure 4 compares the MHF values between SSASC and Class G slurries modified with 5,10 , and 20 vol.\% drilling fluid. The data clearly revealed that the MHF value of unmodified Class $\mathrm{G}$ declined sharply when the content of drilling fluid increased and that of the cement decreased. The data show that adding the drilling fluid decreased the heat released during hydration of conventional well cement likely due to the cement dilution and retardation caused by some mud constituents. The elapsed time at MHF of Class G was extended considerably with an increasing content of drilling fluid. In contrast, the sensitivity of the SSASC slurry to drilling fluid was not important. There was minimal extension of elapsed time for the SSASC (Figure 5). 


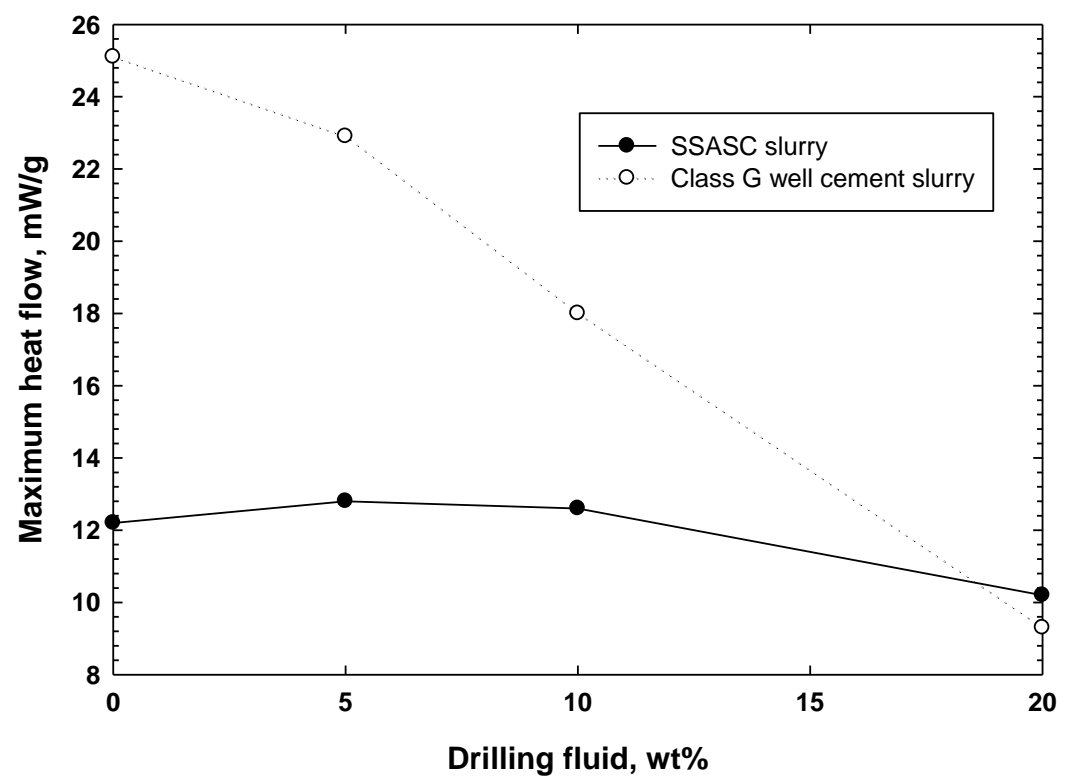

Figure 4. The maximum heat flow energies of SSASC and Class G cement slurries and their blends with the drilling fluid.

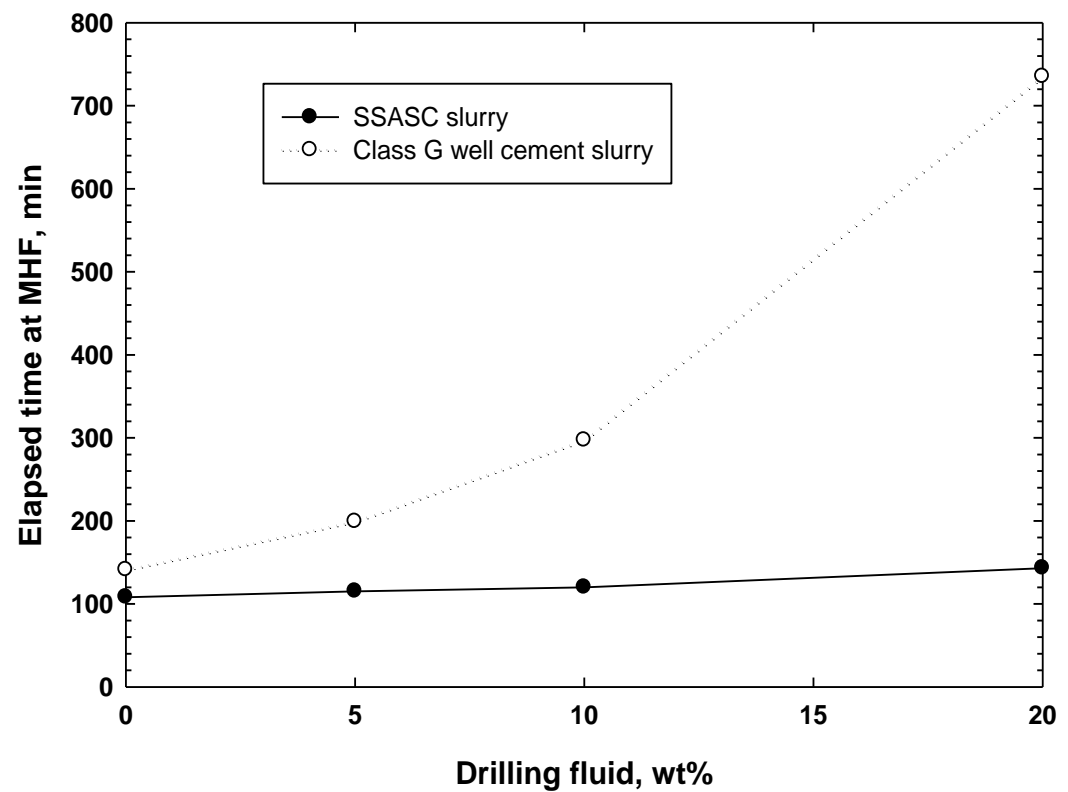

Figure 5. Changes in elapsed time at MHF of SSASC and Class G slurries as a function of drilling fluid content. 


\subsubsection{Compressive strength}

The information obtained in calorimetric experiments described above was correlated directly with the compressive strength of SSASC sealers containing drilling fluid. Figure 6 depicts the changes in the compressive strength of SSASC and Class G well cements as a function of cement/drilling fluid ratio. The compressive strength of SSASC cement increased when $5 \mathrm{vol} . \%$ of the total volume of cement slurry was

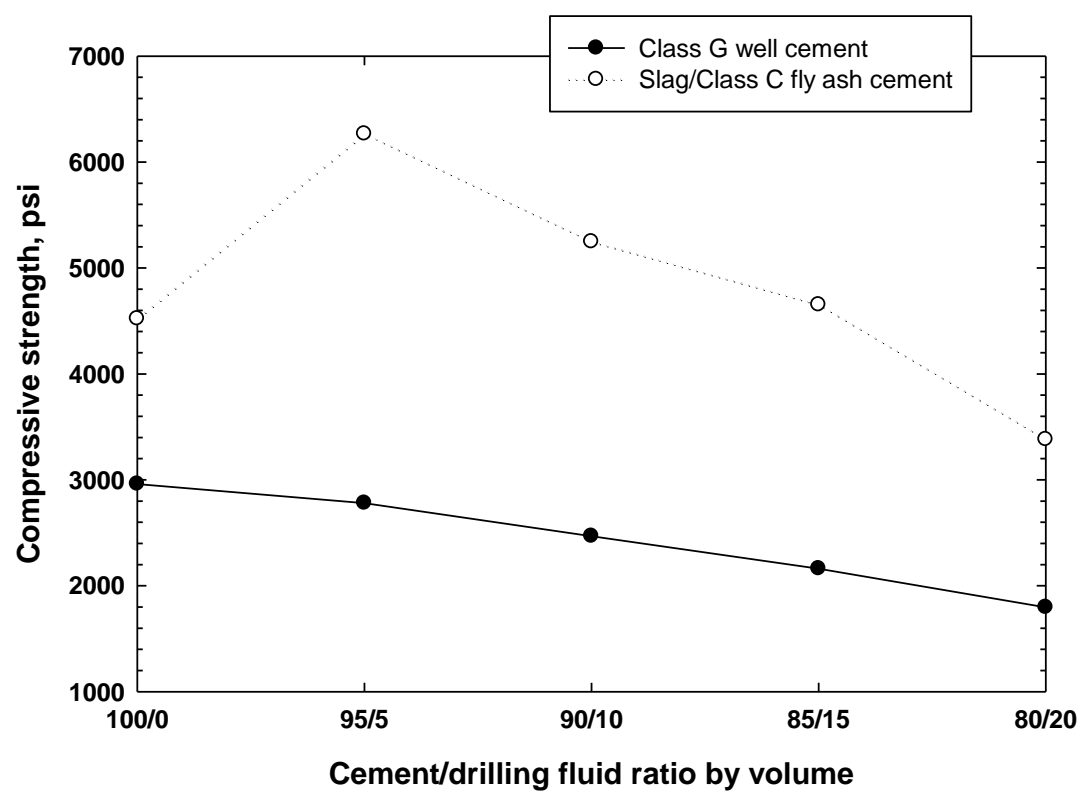

Figure 6. Compressive strength of SSASC and Class G well cements made with 100/0, $95 / 5,90 / 10,85 / 15$, and 80/20 slurry/drilling fluid ratios.

replaced by drilling fluid. As described above, the possible reason for this increase is the alkaline activation of pozzolanic reactions of the slag and fly ash by the caustic soda, which is one of chemical ingredients in drilling fluid. Incorporating $\geq 10 \%$ of drilling fluid into the cement slurries tended to lower their compressive strength because of an increase in the water/cement ratio. At 80/20 cement/drilling fluid ratio, the compressive strength of this cement met the material criteria $>2000$ psi. The drilling fluid considerably lowered the maximum of the hydration reaction heat and significantly extended the elapsed time at the MHF for Class $\mathrm{G}$ cement.

More interestingly, the extent of SSASC cement's compatibility with drilling fluid depended on the content of the sodium silicate activator (Figure 7); namely, increasing the content of sodium silicate offered the improved compressive strength of samples made with 80/20 cement/drilling fluid ratio. Hence, the alkaline activators such as sodium silicate and caustic soda played an important role in governing the extent of sealer's compatibility with the drilling fluid. 


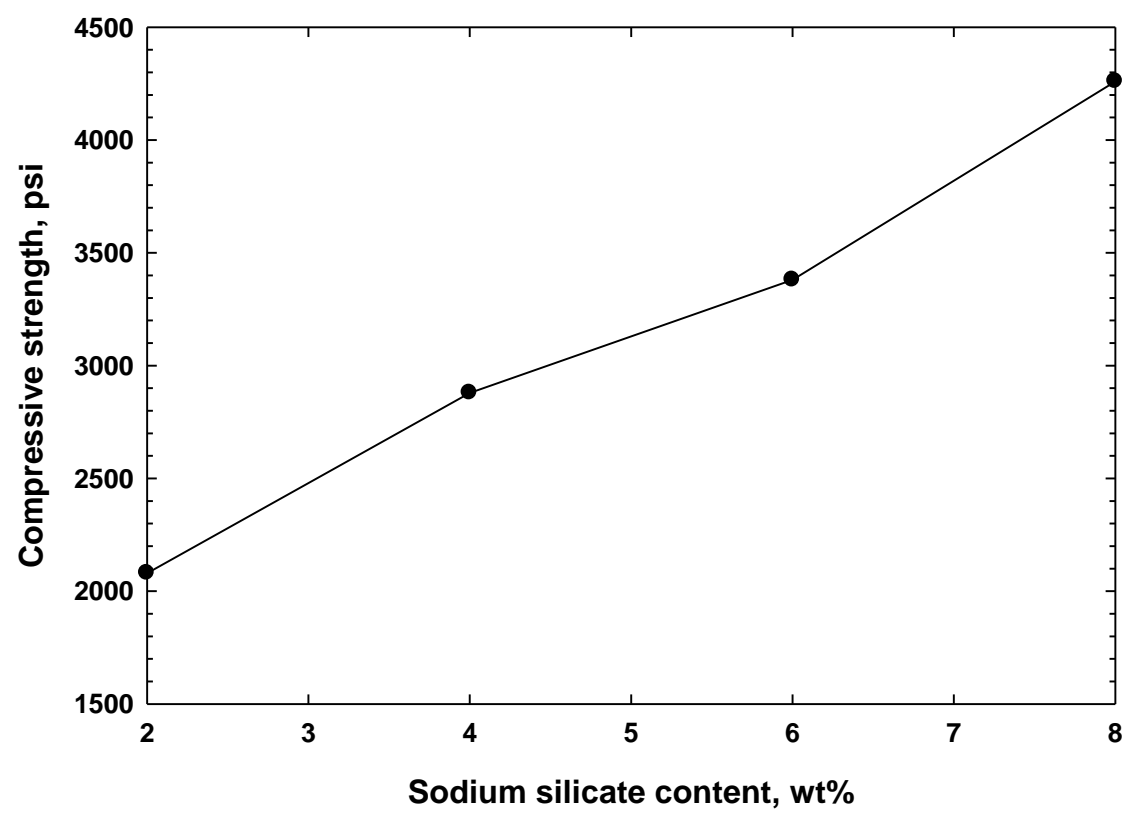

Figure 7. Compressive strength versus content of the sodium silicate activator for sealers made with 80/20 SSASC slurry/drilling fluid ratio.

\subsection{Alkali-catalyzed Self-decomposition of Bridging Additives}

To obtain information on the effect of the SSASC cement on fibers decomposition we surveyed the thermal disintegration of the fibers, treated and non-treated with a $\mathrm{pH} 13.7$ pore solution, after 24 hours at $85^{\circ}$ or $200^{\circ} \mathrm{C}$, in TGA at temperatures ranging from $25^{\circ}$ to $500^{\circ} \mathrm{C}$. The pore solution was extracted by centrifuging the sealer slurry. Since a common well temperature during sealing operations is around $85^{\circ} \mathrm{C}$, it was very important to know whether the fibrous bridging additives in the sealer remained intact at this temperature, thereby ensuring a satisfactory performance in plugging the fractures. When the well temperature is raised to $\geq 200^{\circ} \mathrm{C}$, the bridging additives must decompose concurrently with the self-degradation of cementitious matrix in sealers.

\subsubsection{Acrylic fiber}

Figure 8 shows the TGA and DTGA curves for "as received" acrylic fiber. The curve encompasses two thermal decomposition stages in the temperature range of $25-500^{\circ} \mathrm{C}$ : The first decomposition occurred at $166^{\circ} \mathrm{C}$ and the second one at $281^{\circ} \mathrm{C}$. The total loss in weight of fiber at the test's final temperature of $500^{\circ} \mathrm{C}$ was $86.0 \%$. Figure 9 compares the 


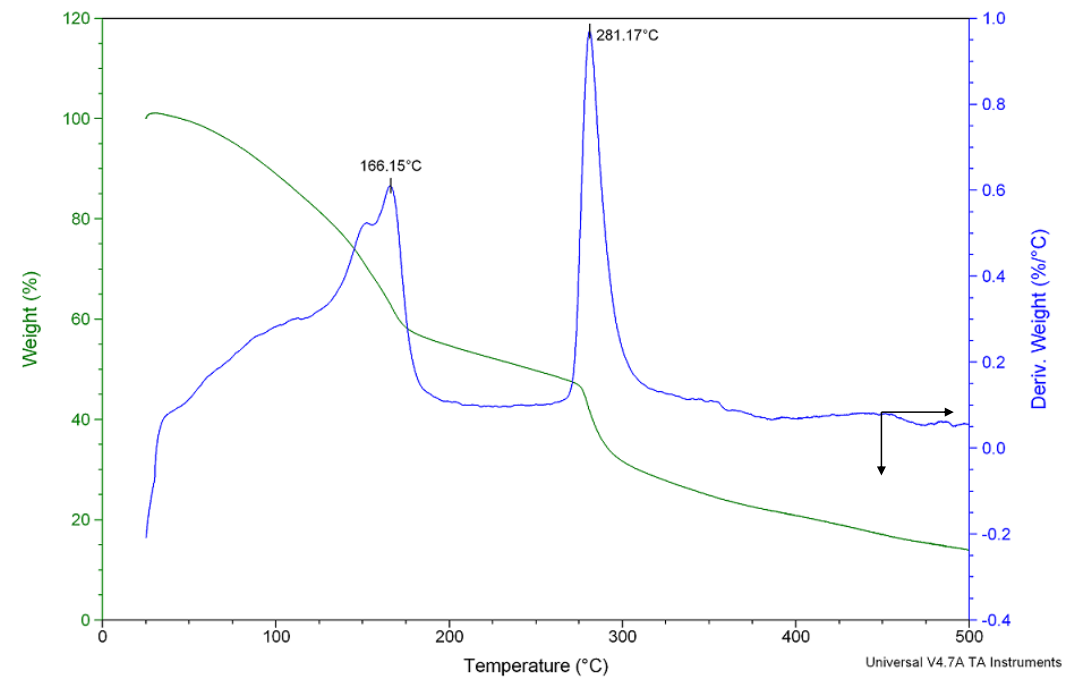

Figure 8. TGA and DTGA curves of "as-received" acrylic fibers.

feature of TGA curves for non-treated, and treated fibers at $85^{\circ}$ and $200^{\circ} \mathrm{C}$, respectively, for 24 hours. When the fiber was treated with $\mathrm{pH} 13.7$ pore solution at $85^{\circ} \mathrm{C}$, this TGA curve was characterized by displaying two different features, compared with that of nontreated one: One was the elimination of the first decomposition stage observed for the non-treated fiber; the other was the decreased total weight loss - only a $39 \%$ total weight loss at $500^{\circ} \mathrm{C}$, underscoring that $54.7 \mathrm{wt} \%$ of the total weight of fiber had been lost during the 24 hour exposure to this pore solution. Such a high loss in weight raised concern about its ability as bridging additives to keep its integrity and plug fractures at $85^{\circ} \mathrm{C}$. The $200^{\circ} \mathrm{C}$ treatment led to a further decomposition, representing the elimination of two-stage decomposition pattern, while a newly emerged thermal decomposition of unknown products was observed at around $430^{\circ} \mathrm{C}$. 


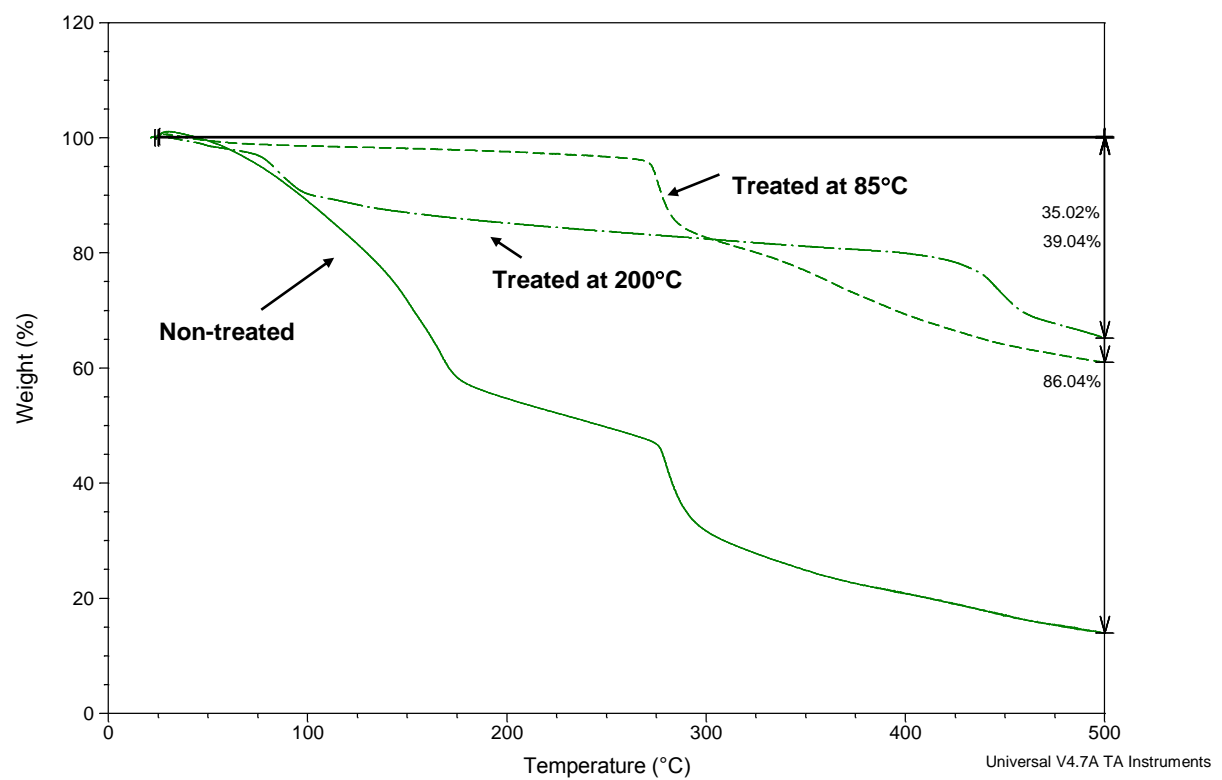

Figure 9. Comparison of TGA curve's features for non-treated, and $\mathrm{pH} 13.7$ pore solution-treated acrylic fiber at $85^{\circ} \mathrm{C}$ and $200^{\circ} \mathrm{C}$.

\subsubsection{PVA fiber}

Unlike acrylic fiber, the "as received" PVA fiber had better thermal stability. In fact, the TGA curve (Figure 10) revealed that the first and second thermal decompositions of this fiber were around $272^{\circ}$ and $378^{\circ} \mathrm{C}$, respectively, corresponding to $\sim 106^{\circ}$ and $\sim 97^{\circ} \mathrm{C}$ higher than that of acrylic fiber at these two decomposition stages. At $500^{\circ} \mathrm{C}$, the fiber registered a total weight loss of $93.8 \%$. Figure 11 compares the TGA curves for nontreated and treated fibers at $85^{\circ}$ and $200^{\circ} \mathrm{C}$. The curve of the fibers treated with pore solution and heated at $85^{\circ} \mathrm{C}$ was similar to that of the non-treated fibers, except for a pronounced loss in weight at temperatures between $\sim 232^{\circ}$ and $\sim 349^{\circ} \mathrm{C}$. The total weight loss of $89.2 \%$ at $500^{\circ} \mathrm{C}$ was only $\sim 5 \%$ lower than that of non-treated one at the same temperature, implying that the susceptibility of this fiber to decomposition caused by exposure to a $\mathrm{pH} 13.7$ pore solution at $85^{\circ} \mathrm{C}$ was minimal. Thus, such minimal decomposition of the fiber seemingly would extend its service lifespan when plugging fractures at $85^{\circ} \mathrm{C}$. At $200^{\circ} \mathrm{C}$, the fibers underwent severe alkali-catalyzed degradation; in fact, compared with that of non-treated fiber, nearly $78 \%$ of the weight of the fibers was eliminated by the treatment. Thus, this fiber possessed all the needed properties as the ideal fibrous bridging additive that serves in plugging the fractures at $85^{\circ} \mathrm{C}$ and selfdecomposes at $200^{\circ} \mathrm{C}$. 


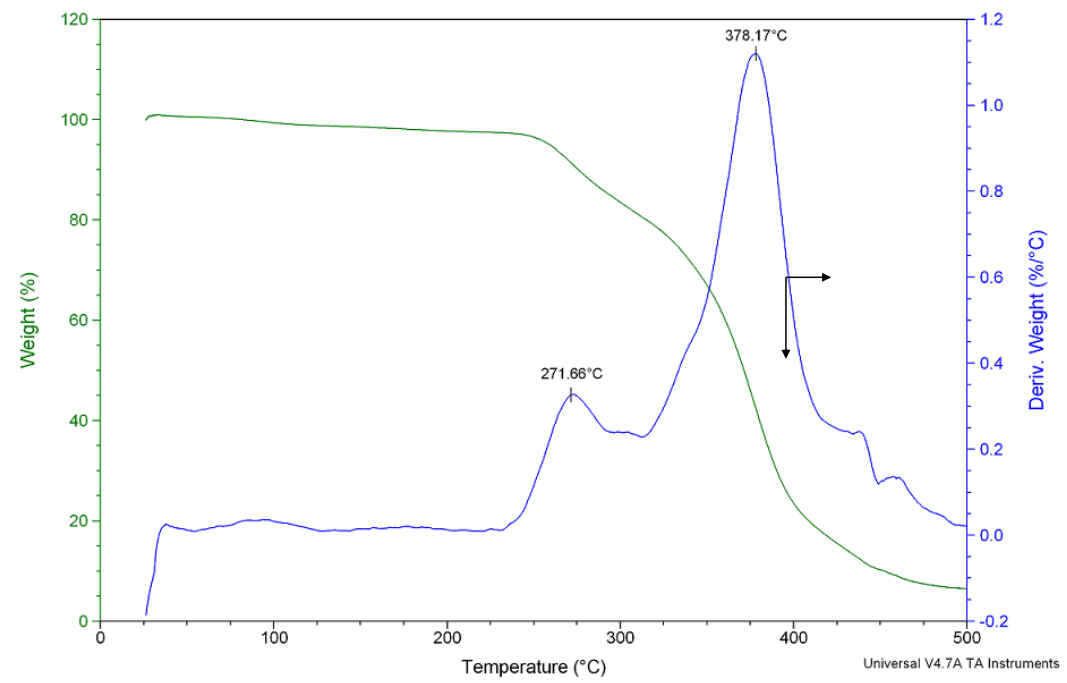

Figure 10. TGA curve for "as-received" PVA fiber.

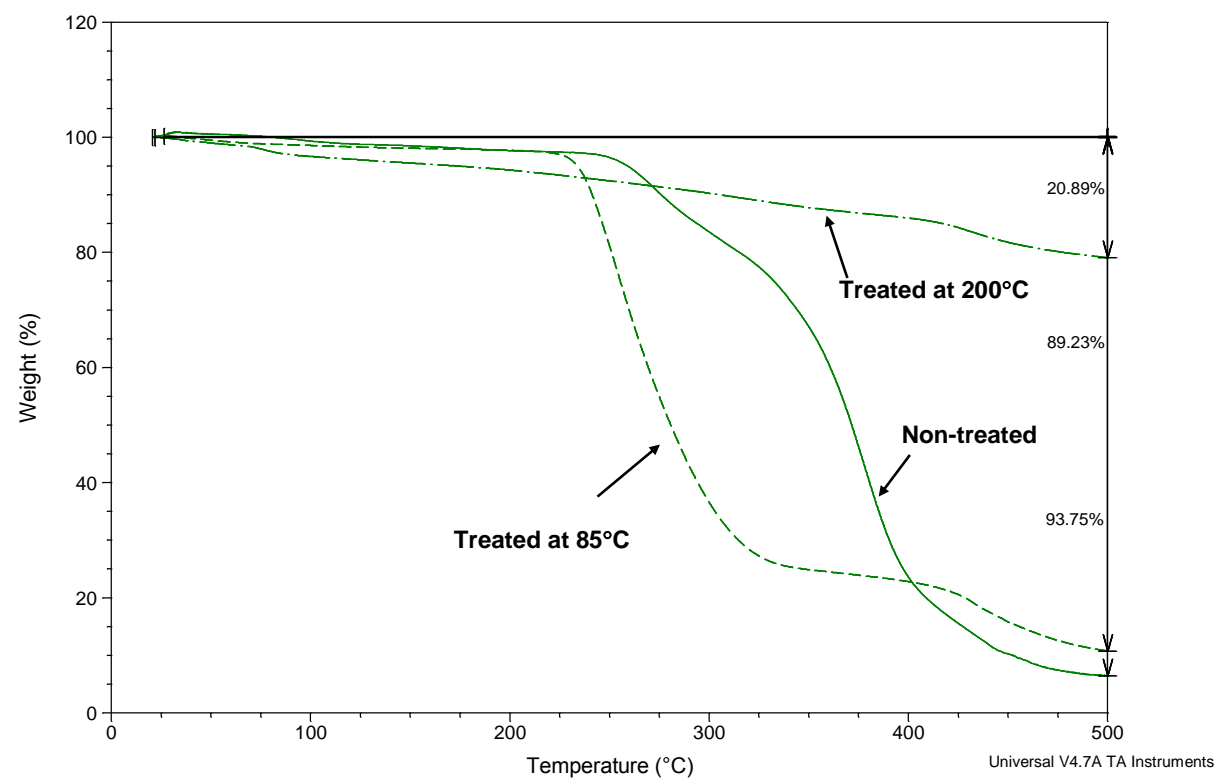

Figure 11. TGA curves for "as-received" PVA fibers and fiber treated with pore solution at $85^{\circ} \mathrm{C}$ and at $200^{\circ} \mathrm{C}$. 


\subsubsection{Nylon fiber}

The nylon fiber displayed better thermal stability than PVA. Its major thermal decomposition was evident between $\sim 400^{\circ}$ and $500^{\circ} \mathrm{C}$ (Figure 12). Similar to PVA TGA results were observed after fibers exposure to the $\mathrm{pH} 13.7$ pore solution at $85^{\circ}$ and $200^{\circ} \mathrm{C}$ (Figure 13). The fibers withstood the alkali attack at $85^{\circ} \mathrm{C}$, but degraded at $200^{\circ} \mathrm{C}$. For the latter fact, the comparison of weight loss between the non-treated and $200^{\circ} \mathrm{C}$-treated fibers at $500^{\circ} \mathrm{C}$ on the TGA curves demonstrated that nearly $85 \mathrm{wt} \%$ of fiber was eliminated after $200^{\circ} \mathrm{C}-24 \mathrm{hr}$-treatment.

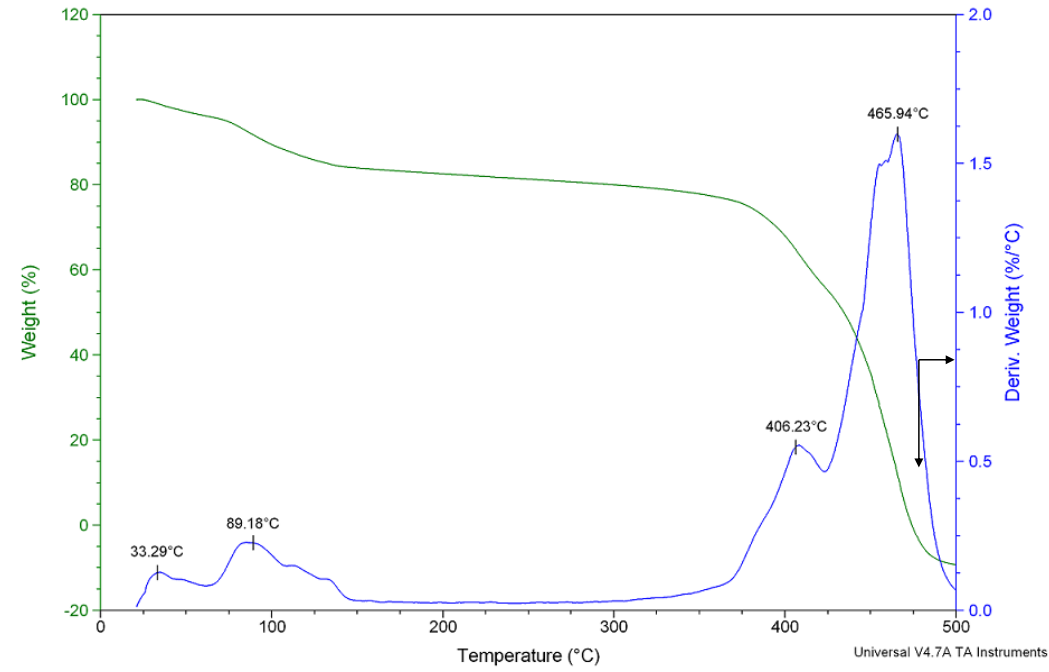

Figure 12. TGA and DTGA curves for "as received" nylon fiber. 


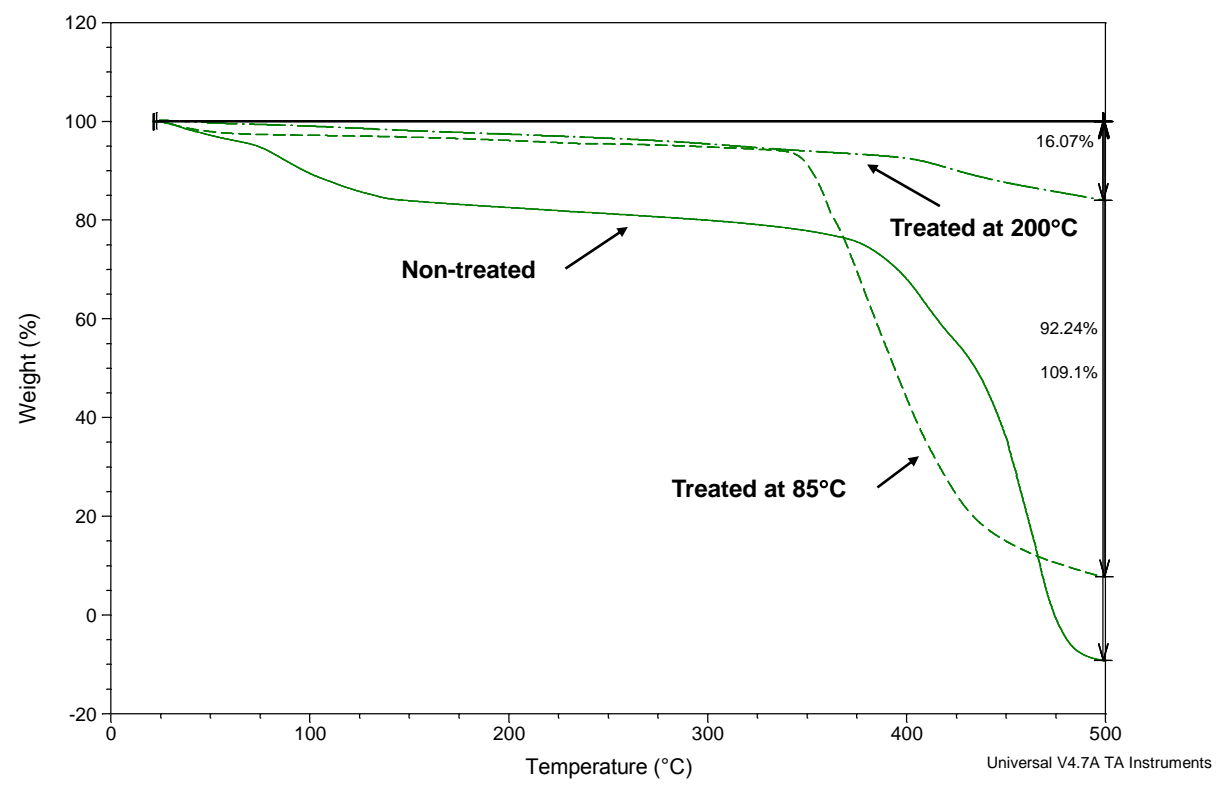

Figure 13. Comparison between TGA curves of non-treated and $85^{\circ} \mathrm{C}$ - or $200^{\circ} \mathrm{C}$-treated nylon fibers.

\subsubsection{PE fiber}

As is evident from TGA curve (Figure 14), non-treated PE fiber showed a typical singlestage decomposition pattern representing one decomposition temperature at $469^{\circ} \mathrm{C}$, which was the highest temperature for breakdown among all organic fibers used in this test series. Again, this fiber was identified as one of ideal alternative bridging fibers that were sustainable at $85^{\circ} \mathrm{C}$ and degradable at $200^{\circ} \mathrm{C}$ (Figure 15 ).

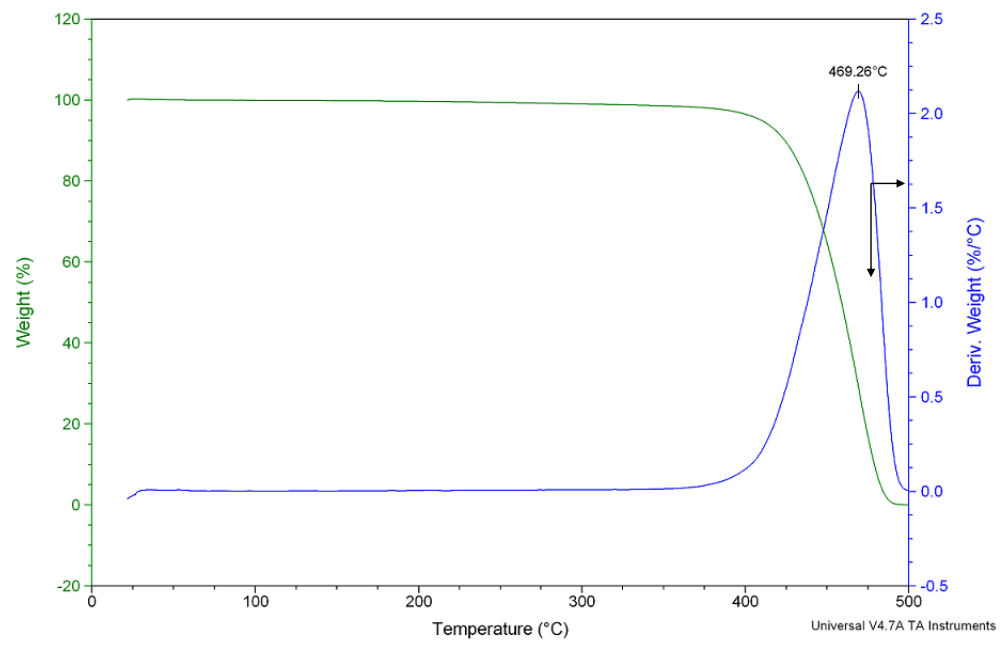

Figure 14. Thermal decomposition of the PE fiber. 


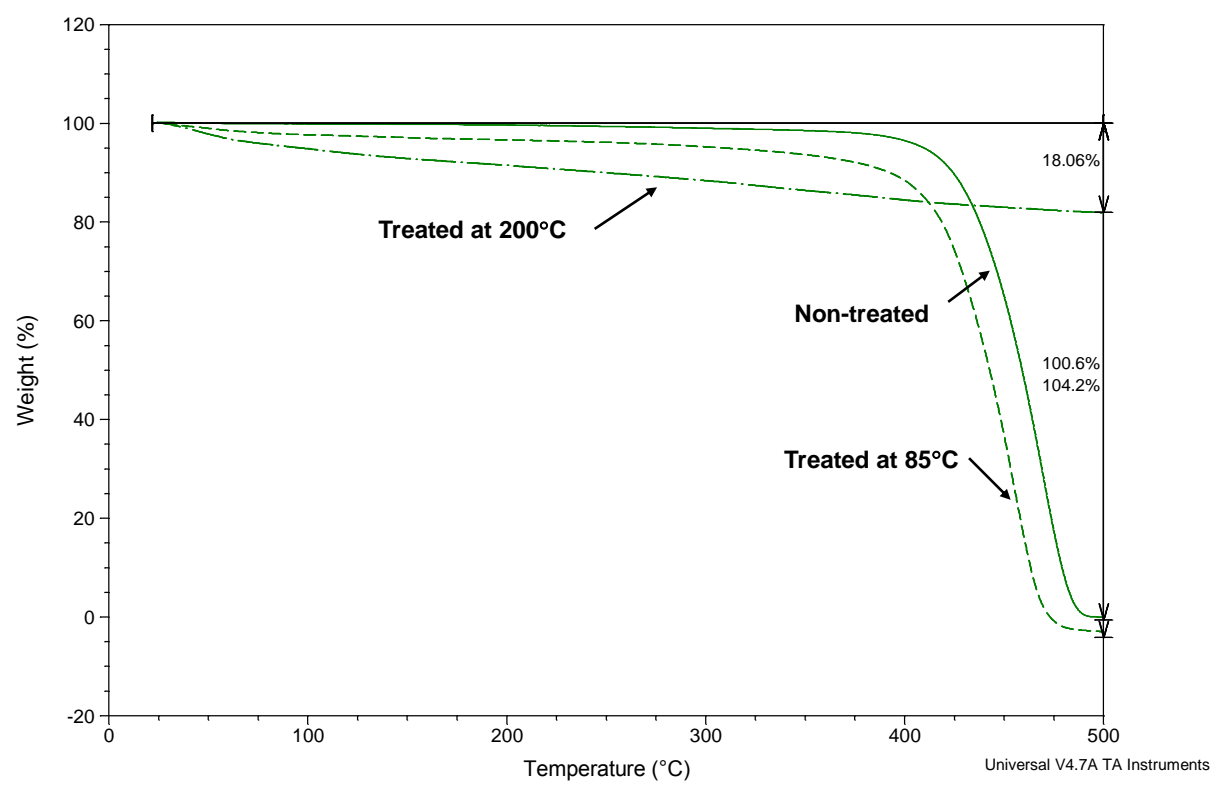

Figure 15 . Weight loss of non-treated and $85^{\circ} \mathrm{C}$ - or $200^{\circ} \mathrm{C}$-treated PE fibers.

Figure 16 summarizes all information on the alkali-catalyzed weight loss at $85^{\circ}$ and $200^{\circ} \mathrm{C}$ of the fibers described above. All fibers, except for acrylic, met our criteria for a degradable bridging material.

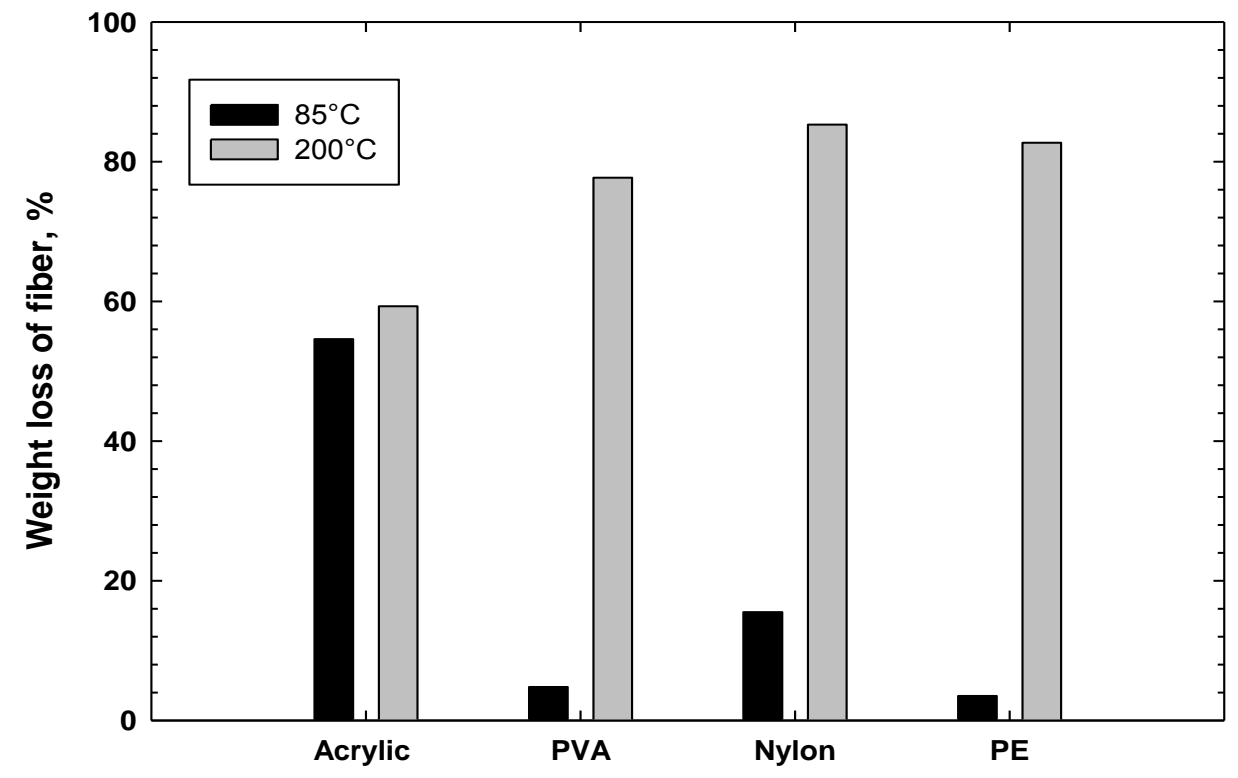

Figure 16. Weight loss of acrylic, PVA, nylon, and PE fibers treated with $\mathrm{pH} 13.7$ pore solution at $85^{\circ} \mathrm{C}$ and $200^{\circ} \mathrm{C}$. 


\subsection{Plugging performance in slots}

Next we focused on evaluating fibers ability to plug the slots of two different heights, 0.08 and 0.25 inches, under pressures of up to 700 psi.

Table 1 shows the results from 0.08 in. slot test displaying the plugging behaviors of sealers with different fibers under the different pressures. As expected, the sealer slurry without fibers was completely ineffective in plugging the slot, in fact, even at the lowest pressure of $20 \mathrm{psi}$, it filtrated a100 \% of the sealer failing to plus the failure. In contrast, incorporating a $25 \mathrm{~mm}$-long acrylic fiber at $0.3 \mathrm{wt} \%$ into this slurry improved its plugging efficiency under pressure of up to $50 \mathrm{psi}$, although $20.5 \mathrm{wt} \%$ of the total weight of fiber-containing slurry filtrated through 6-in. long slot nozzle during plugging operation at $50 \mathrm{psi}$. Beyond this pressure, this fiber was not effective in plugging the fracture. Increasing fiber concentration to $1 \mathrm{wt} . \%$ resulted in slurry with too high consistency to be mixed in a blender. Thus, no further tests were performed with the acrylic fiber.

Table 1. Ability of various fibrous bridging additives to plug 0.08 in. high slot

\begin{tabular}{|c|c|c|c|c|c|c|c|}
\hline \multirow[t]{2}{*}{ Fiber } & \multirow{2}{*}{$\begin{array}{c}\text { Content, } \\
\text { wt } \%\end{array}$} & \multicolumn{6}{|c|}{ Filtration loss of sealer, wt $\%$} \\
\hline & & $20 \mathrm{psi}$ & $50 \mathrm{psi}$ & $100 \mathrm{psi}$ & $200 \mathrm{psi}$ & $500 \mathrm{psi}$ & $700 \mathrm{psi}$ \\
\hline Non & 0 & 100 & 100 & 100 & 100 & 100 & 100 \\
\hline \multirow{3}{*}{$\begin{array}{l}\text { Acrylic } \\
(25 \mathrm{~mm})\end{array}$} & 0.1 & 11.9 & 100 & 100 & 100 & 100 & 100 \\
\hline & 0.3 & 4.3 & 20.5 & 100 & 100 & 100 & 100 \\
\hline & 1.0 & $\begin{array}{l}\text { Too stiff } \\
\text { to mix }\end{array}$ & & & & & \\
\hline \multirow{3}{*}{$\begin{array}{l}\text { PVA } \\
(6 \mathrm{~mm})\end{array}$} & 0.5 & 100 & 100 & 100 & 100 & 100 & 100 \\
\hline & 1.0 & 7.3 & 1.9 & 0 & 0 & 0 & 0 \\
\hline & 2.0 & 5.3 & 0 & 0 & 0 & 0 & 0 \\
\hline \multirow{3}{*}{$\begin{array}{l}\text { Nylon } \\
(6 \mathrm{~mm})\end{array}$} & 0.5 & 100 & 100 & 100 & 100 & 100 & 100 \\
\hline & 1.0 & 5.9 & 8.9 & 21.7 & 55.9 & 100 & 100 \\
\hline & 2.0 & 0 & 0 & 0 & 0 & 0 & 0 \\
\hline \multirow[t]{3}{*}{ PE (6mm) } & 0.5 & 100 & 100 & 100 & 100 & 100 & 100 \\
\hline & 1.0 & 22.4 & 35.9 & 100 & 100 & 100 & 100 \\
\hline & 2.0 & 14.5 & 6.9 & 0 & 0 & 0 & 0 \\
\hline
\end{tabular}

A 6 mm-long PVA fiber plugged the 0.08 in. slot at pressures up to 700 psi when added at concentrations 1 and $2 \mathrm{wt} . \%$. Small amounts of slurry were lost at pressures up to 50 psi but not at higher pressure. To understand the improved plugging at higher pressures we examined the appearance of the sealer plugged in 1 in. wide x 6 in. long x 0.08 in. high slot (Figure 17). Of particular interest was the creation of the cohesive mass of highly concentrated fibers with slurry at the inlet of the slot. Hence, we rationalized that such a successful plugging performance was due to the assemblage of impervious 
coalescing layers of fibers with slurry under pressure. This assembled layer played essential role in preventing a further infiltration of slurry through the slot. A plugging mechanism similar to that of PVA was observed from $2.0 \mathrm{wt} \%$ nylon and PE fibers of 6 $\mathrm{mm}$ long; namely, there was no loss of slurry at pressures $\geq 100 \mathrm{psi}$.

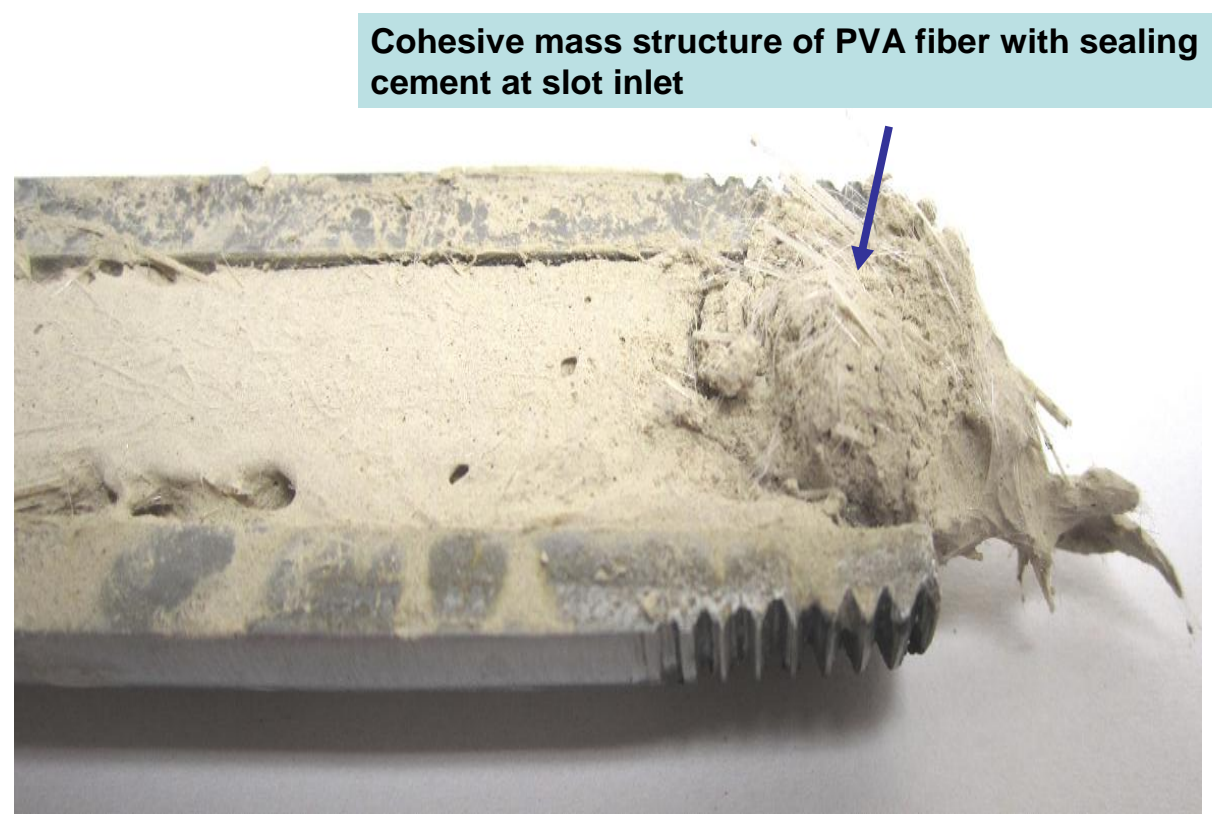

Figure 17. Appearance of PVA fiber-bridging sealer plugged at the inlet of 1 in. wide $x 6$ in. long $\mathrm{x} 0.08$ in. high slot.

When these $6 \mathrm{~mm}$-length fibers were applied to 0.24 in.-high slot, the three times larger slot than that of 0.08 in. one, we recorded that these fibers were unsuitable for such a large slot. Hence, in testing the plugging of 0.24 in.-slot, we employed two other methods: One was the use of single long 19 mm PVA- and nylon- fibers; the other was the combination of $19 \mathrm{~mm}$-long fibers with short ones of $6 \mathrm{~mm}$.

In the first approach, the $19 \mathrm{~mm}$ PVA fibers at $2 \mathrm{wt} \%$, which was an upper limit in preparing workable slurry, failed to plug a $0.24 \mathrm{in}$. slot (Table 2) at pressures above 100 psi. We also tested the effect of $6 \mathrm{~mm}$ fibers at $4 \mathrm{wt} \%$, corresponding to the maximum content. But, this slurry failed at the lowest pressure of 20 psi. Thus, there was no benefit gained by using single long or short PVA fibers in plugging a 0.24 in. slot. A similar result was obtained from the single fiber system of nylon (not shown). In contrast, we successfully plugged the slot with our second approach that combined short- and longfibers. Additionally, the proportion of short to long fibers was important to obtain good plugging performance of the sealer; for instance, a ratio of 2 part/1 part short/long fibers resulted in a better performance than a ratio with 1 part / 2 part short/long fibers. In fact, a combined fiber system consisting of $1.0 \mathrm{wt} \% 6 \mathrm{~mm}$ PVA or nylon fibers and $0.5 \mathrm{wt} \% 19$ 
mm PVA fibers adequately plugged a 0.24 in. slot, reflecting a zero filtrate at $\geq 200$ psi pressure.

Table 2. Comparison of plugging performances of sealers made by the combination of 19 mm-length PVA and 6 mm-length PVA, nylon, or PE fibers for 0.24 in. slot

\begin{tabular}{|c|c|c|c|c|c|c|c|}
\hline \multirow[t]{2}{*}{ Fiber } & \multirow{2}{*}{$\begin{array}{l}\text { Content, } \\
\text { wt\% }\end{array}$} & \multicolumn{6}{|c|}{ Filtration loss of sealer, wt $\%$} \\
\hline & & $20 \mathrm{psi}$ & $50 \mathrm{psi}$ & $100 \mathrm{psi}$ & $200 \mathrm{psi}$ & $500 \mathrm{psi}$ & $700 \mathrm{psi}$ \\
\hline PVA (6mm) & 4 & 100 & 100 & 100 & 100 & 100 & 100 \\
\hline $\begin{array}{l}\text { PVA (19 } \\
\mathrm{mm})\end{array}$ & 2 & 17.4 & 25.8 & 100 & 100 & 100 & 100 \\
\hline $\begin{array}{l}\text { PVA (19mm) } \\
\text { PVA (6mm) }\end{array}$ & $\begin{array}{l}1.0 \\
0.5\end{array}$ & 1.6 & 0 & 0 & 100 & 100 & 100 \\
\hline $\begin{array}{l}\text { PVA (19mm) } \\
\text { PVA (6mm) }\end{array}$ & $\begin{array}{l}0.5 \\
1.0\end{array}$ & 10.6 & 0 & 0 & 0 & 0 & 0 \\
\hline $\begin{array}{l}\text { PVA }(19 \mathrm{~mm}) \\
\text { Nylon } \\
(6 \mathrm{~mm})\end{array}$ & $\begin{array}{l}0.5 \\
1.0\end{array}$ & 6.4 & 2.9 & 1.4 & 0 & 0 & 0 \\
\hline $\begin{array}{l}\text { PVA (19 } \\
\mathrm{mm}) \\
\mathrm{PE}(6 \mathrm{~mm})\end{array}$ & 0.5 & 7.1 & 14.9 & 27.5 & 100 & 100 & 100 \\
\hline
\end{tabular}

Table 3 summarizes the plugging effect of $19 \mathrm{~mm}$ nylon fiber combined with $6 \mathrm{~mm}$ nylon or PVA fibers as a function of pressure. These data strongly supported the concept that the plugging performance of long/short fiber combinations depended on their ratio; the ratio of 1 part / 2 parts long nylon /short nylon or PVA fibers was responsible for plugging adequately a 0.24 in. slot. 
Table 3. Effectiveness of sealers made by combing $19 \mathrm{~mm}$-long nylon fibers and $6 \mathrm{~mm}$ long nylon or PVA fibers in plugging a 0.24 in. slot

\begin{tabular}{|c|c|c|c|c|c|c|c|}
\hline \multirow[t]{2}{*}{ Fiber } & \multirow{2}{*}{$\begin{array}{c}\text { Content, } \\
\text { wt } \%\end{array}$} & \multicolumn{6}{|c|}{ Filtration loss of sealer, wt $\%$} \\
\hline & & $20 \mathrm{psi}$ & $50 \mathrm{psi}$ & $100 \mathrm{psi}$ & $200 \mathrm{psi}$ & $500 \mathrm{psi}$ & $700 \mathrm{psi}$ \\
\hline $\begin{array}{l}\begin{array}{l}\text { Nylon } \\
(19 \mathrm{~mm})\end{array} \\
\text { Nylon } \\
(6 \mathrm{~mm})\end{array}$ & $\begin{array}{l}0.5 \\
1.0\end{array}$ & 0 & 0 & 0 & 0 & 0 & 0 \\
\hline $\begin{array}{l}\text { Nylon } \\
(19 \mathrm{~mm})\end{array}$ & $\begin{array}{l}0.5 \\
1.0\end{array}$ & 2.2 & 0 & 0 & 0 & 0 & 0 \\
\hline 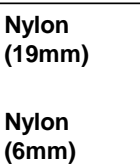 & $\begin{array}{l}1.0 \\
0.5\end{array}$ & 0 & 0 & 0 & 20.2 & 100 & 100 \\
\hline $\begin{array}{l}\begin{array}{l}\text { Nylon } \\
(19 \mathrm{~mm})\end{array} \\
\text { PVA }(6 \mathrm{~mm})\end{array}$ & $\begin{array}{l}1.0 \\
0.5 \\
\end{array}$ & 0 & 2.8 & 11.2 & 100 & 100 & 100 \\
\hline
\end{tabular}

\subsection{Compressive strength and toughness}

Based upon this information, next we determined the compressive-strength and toughness of six potential fiber-bridged sealer systems after autoclaving them for 24 hours at $85^{\circ} \mathrm{C}$. Among these systems were single PVA $(6 \mathrm{~mm})$, single nylon $(6 \mathrm{~mm}), 2 / 1$ PVA $(6 \mathrm{~mm}) / \mathrm{PVA}(19 \mathrm{~mm})$ ratio, $2 / 1 \mathrm{PVA}(6 \mathrm{~mm}) /$ nylon $(19 \mathrm{~mm})$ ratio, $2 / 1$ nylon $(6$ $\mathrm{mm}) /$ nylon $(19 \mathrm{~mm})$ ratio, and 2/1 nylon $(6 \mathrm{~mm}) / \mathrm{PVA}(19 \mathrm{~mm})$ ratio. For comparison, as our control, we tested a non-bridged sealer prepared under the same condition.

Figure 18 depicts the compressive stress-strain curves for these sealers. The brittle nature of the non-bridged sealer is evident from the sudden descent of the curve shortly after its maximum. In other words, once, the cracks were generated in sealer at its yield point, these cracks rapidly propagated, leading to its instant failure. In contrast, adding the 6 mm-long PVA fibers significantly improved the sealer's ductility. As is evident from curve's features, there was no sign of a sudden drop in the curve after reaching the yield point of the sealer, instead the compressive strain gradually declined. Thus, incorporating the $6 \mathrm{~mm}$ PVA fibers seemingly restrained the propagation of cracks generated in sealer, conferring a good ductile property on sealer. However, this fiber did not improve the compressive strength of the sealer, compared with that of the control; in fact, its maximum strength of $10.3 \mathrm{MPa}$ was nearly $43 \%$ lower than that of the control. A similar curve's feature, except for a lower 


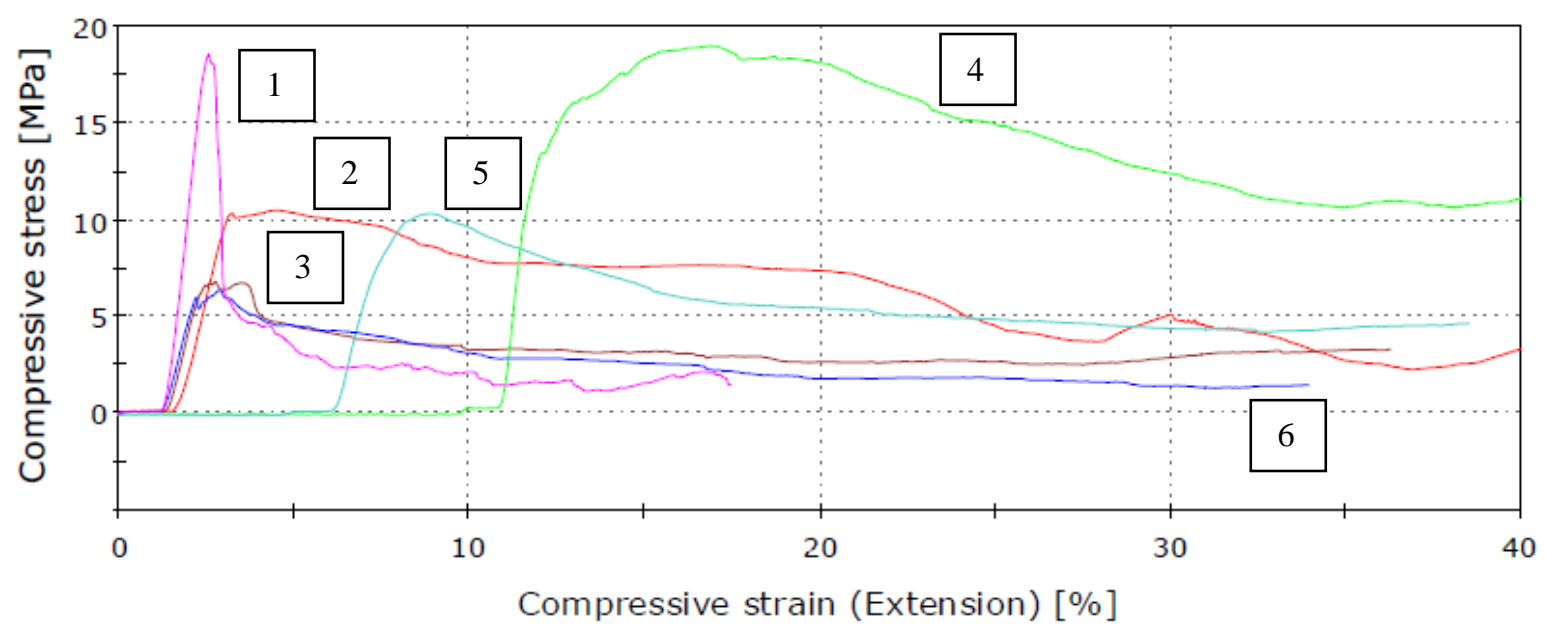

Figure 18. Compressive stress-strain curves for control (1), 6mm PVA (2), 6mm nylon (3), 2/1 6mm PVA/19mm PVA ratio (4), 2/1 6mm PVA/19mm nylon ratio (5), and 2/1 $6 \mathrm{~mm}$ nylon/19mm PVA ratio (6).

maximum compressive strength, was observed for the sealer containing the nylon fiber with the same length and amount as that of PVA, suggesting that fiber offered some improvement of sealer's ductility. The highest compressive-strength along with extended strain was obtained from the sealer bridged with the combined fibers at the ratio of $2 / 1$ PVA (6 mm)/PVA (19 mm), representing an outstanding ductility. These data also revealed that when the PVA fibers in the combined fiber systems were replaced with nylon, the compressive strength strongly reduced compared with that of $100 \%$ PVA fiber system. This finding seems to demonstrate that the PVA fibers adhere better to the cementitious sealer than do the nylon fibers.

To obtain quantitative data on the magnitude of ductility, we determined the compressive toughness, $\mathrm{J} / \mathrm{mm}^{3}$, as the total energy consumed during the completion of sealer's compressive failure; it was computed from the enclosed area of the compressive stressstrain curve with the baseline extending between the beginning and the end of the peak (Figure 19). Figure 20 shows the compressive-strength and -toughness of fiber-bridged sealers and non-bridged ones after autoclaving for 24 hours at $85^{\circ} \mathrm{C}$. For non-bridged sealer noted as the control, it developed the compressive strength of $2263 \mathrm{psi}$ and had the compressive toughness of $0.4 \mathrm{~J} / \mathrm{mm}^{3} \times 10^{3}$. This value of compressive strength declined by $28 \%$ to 1625 psi when sealer was bridged with $6-\mathrm{mm}$ long PVA fibers, whereas the compressive toughness markedly increased by more than 4-fold to $1.65 \mathrm{~J} / \mathrm{mm}^{3} \times 10^{3}$ compared with that of the control. This fact clearly showed that PVA fibers contribute significantly to enhancing the sealer's ductility, but, it did not improve the compressive strength. Adding 6-mm long nylon fibers was not as effective in improving toughness as were the PVA fibers. Further, the compressive strength of nylon-bridged sealer fell nearly $33 \%$, compared with that containing PVA fibers. 


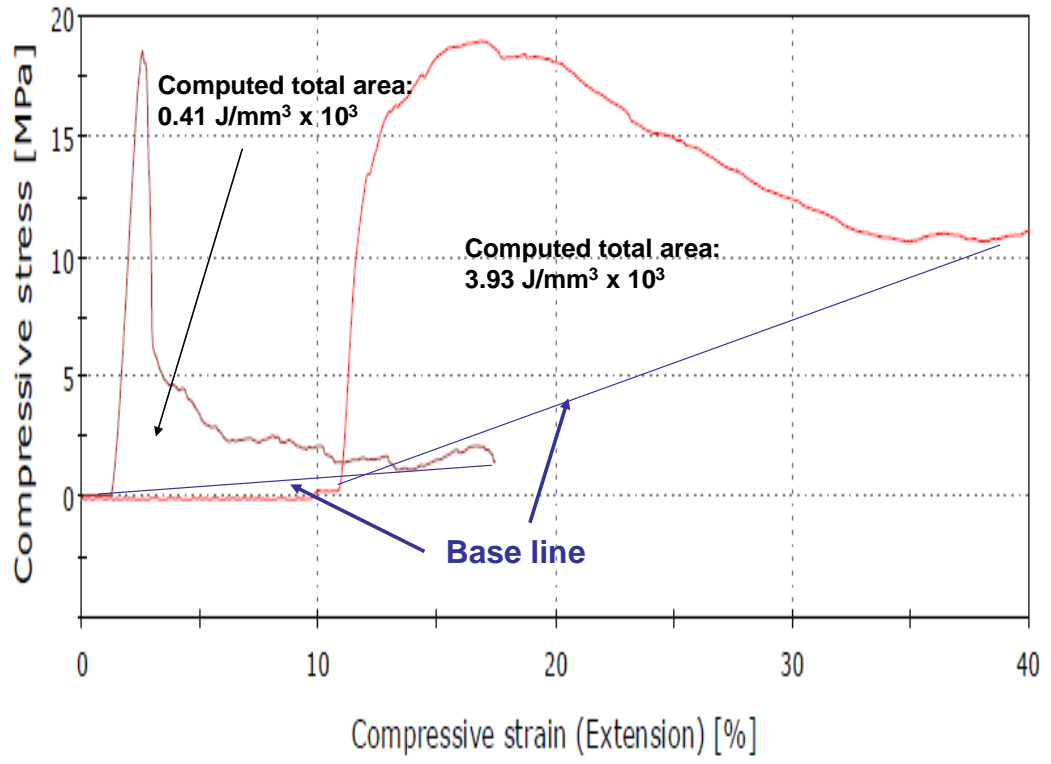

Figure 19. Total area along with the base line made on compressive stress-strain curves for computing compressive toughness.

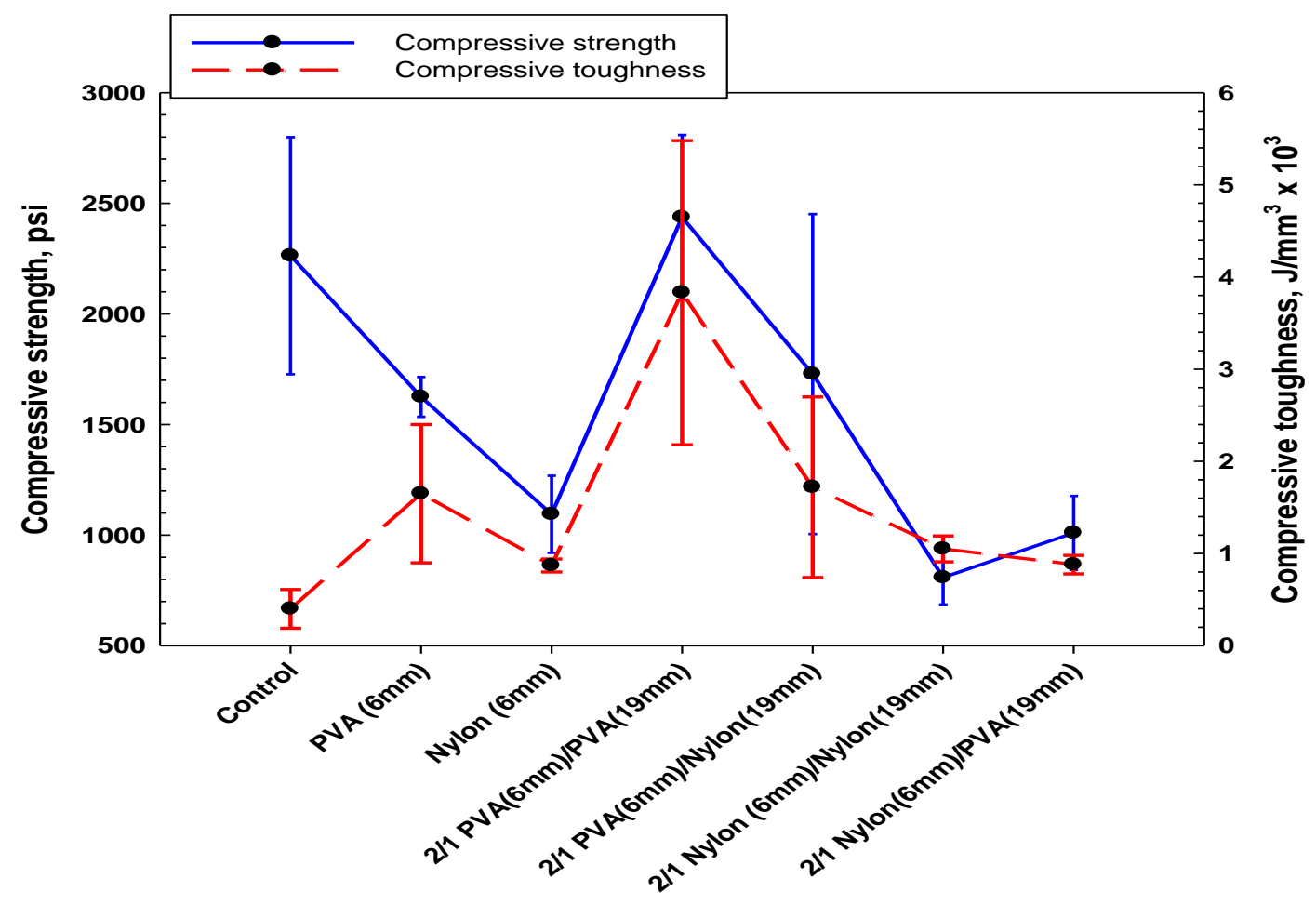

Figure 20. Compressive-strength and- toughness for non-bridged and fiber-bridged sealers after autoclaving for 24 hours at $85^{\circ} \mathrm{C}$. 
As expected, the combined fiber system of 2/1 PVA $(6 \mathrm{~mm}) / \mathrm{PVA}(19 \mathrm{~mm})$ greatly improved compressive toughness; in fact, the value of $3.8 \mathrm{~J} / \mathrm{mm}^{3} \times 10^{3}$ was $9.5-$ and 2.3fold higher than those of non-bridged and single PVA (6 mm)- bridged sealers, respectively, while this fiber system also gave higher sealer's compressive strength. On the other hand, replacing the PVA fibers by nylon fibers decreased both compressivestrength and-toughness. For instance, the compressive strength of 1728 psi and toughness of $1.7 \mathrm{~J} / \mathrm{mm}^{3} \times 10^{3}$ for $2 / 1$ PVA $(6 \mathrm{~mm}) /$ nylon $(19 \mathrm{~mm})$ ratio-bridged sealer corresponded to $29 \%$ and $55 \%$ decline compared to those of the $2 / 1$ PVA $(6 \mathrm{~mm}) / \mathrm{PVA}$ $(19 \mathrm{~mm})$ ratio-made sealer. Further reduction of these mechanical properties was noted from the 2/1 nylon $(6 \mathrm{~mm}) /$ nylon $(19 \mathrm{~mm})$ ratio- and 2/1 nylon $(6 \mathrm{~mm}) /$ PVA $(19 \mathrm{~mm})$ ratio-bridged sealers.

Thus, we found that PVA fiber not only assured the satisfactory plugging performance of the sealer in slot, but also significantly improved the sealer's compressive toughness.

\subsection{Self-degradation of bridged sealers}

Before evaluating the self-degrading performance of PVA- and nylon-fiber bridging sealers, we explored the alteration in morphological features of these fibers after exposing them to $\mathrm{pH} 13.7$ pore solution for 24 hours at $200^{\circ} \mathrm{C}$. Figure 21 exhibits the SEM images of PVA fibers before and after the exposure. The images demonstrate that the fibrous structure was altered dramatically into the flake-like fragments with the size ranging from $\sim 2 \mu \mathrm{m}$ to $\sim 10 \mu \mathrm{m}$ by alkali-catalyzed decomposition of the fibers at this temperature. Since the TGA test showed that $\sim 73 \%$ of the total weight of PVA fiber was eliminated after such exposure, this SEM image shows the non-volatile remnants of the fibers. In contrast the SEM image of the alkali-treated, thermally decomposed nylon fiber revealed a Swiss chesses-like morphology encompassing copious craters (Figure 22). Their formation may be caused by the volatile compounds emanated during the fiber's decomposition. This image also pointed to the self-agglomerating characteristics of the by-products from the decomposition of nylon fiber. However, there was no experimental evidence as to whether such agglomeration took place in a decomposition period at $200^{\circ} \mathrm{C}$, in a cooling period from $200^{\circ} \mathrm{C}$ to room temperature, or both.

Nevertheless, such morphological alteration of the decomposed fibers was one important factor governing the degradation performance of sealers containing bridging additives. To understand this factor, we prepared the PVA (6 mm)-and nylon $(6 \mathrm{~mm})$-bridged sealers by autoclaving them at $85^{\circ} \mathrm{C}$ for 24 hours, and then the autoclaved sealers were placed in an oven at $200^{\circ} \mathrm{C}$ for 24 hours. Afterwards, the heated sealers were directly immersed for 1 hour into water at room temperature. For visualizing the self-degradation, we gently broke these immersed sealers by hand (Figure 23). 


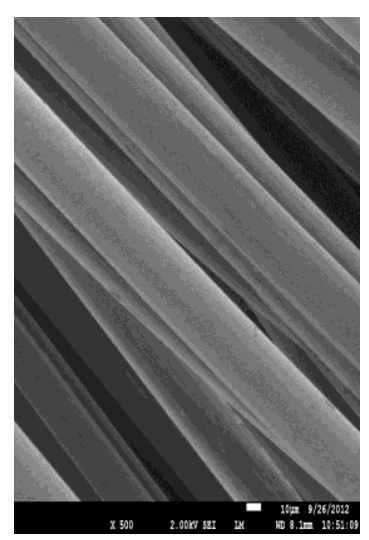

PVA Fibers

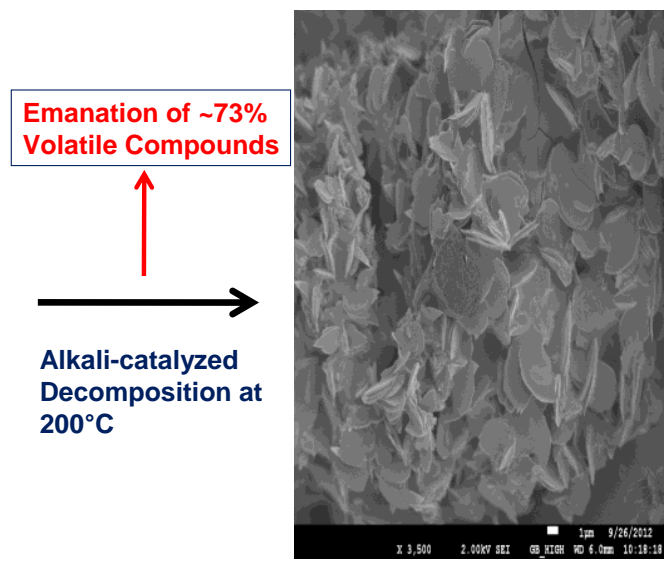

$\sim 21 \%$ Flake-like Nonvolatile Compounds

Figure 21. Alteration of the morphology of PVA fibers after exposure to $\mathrm{pH} 13.7$ pore solution at $200^{\circ} \mathrm{C}$ for 24 hours.

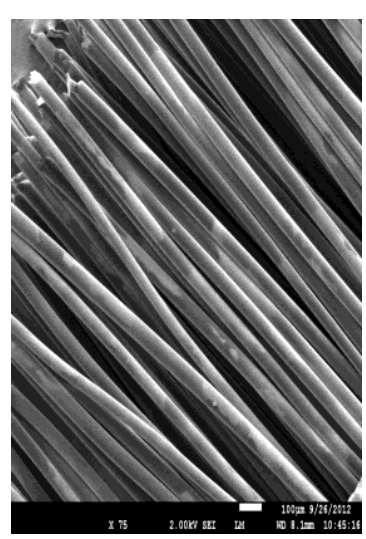

Nylon Fibers

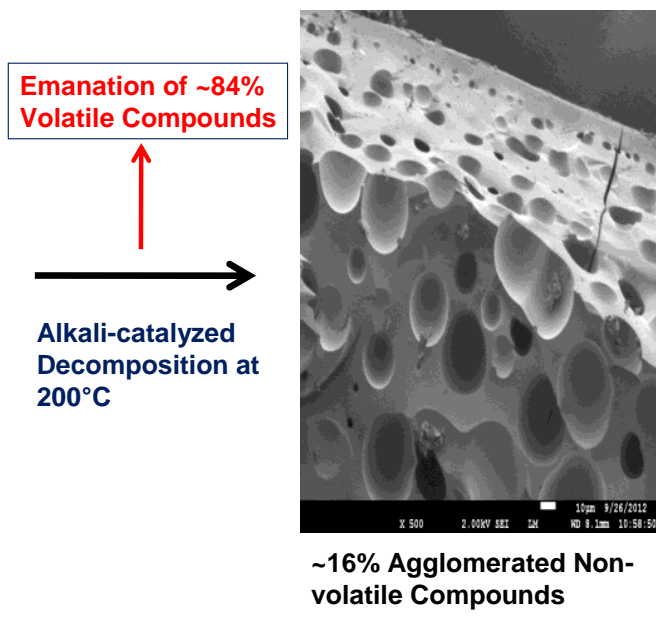

Figure 22. Morphological alteration of nylon fibers treated with $\mathrm{pH} 13.7$ pore solution at $200^{\circ} \mathrm{C}$.

As is evidenced from these photos, both the PVA- and nylon-bridged sealers were crumbled easily. However, the sealer with the PVA fibers could be broken into much smaller fragments after the high temperature exposure. We believe that the PVA fibers provided better degradation of the sealer because of their morphological transformation into flake-like fragments during the high temperature treatment. Such alteration aided in 
converting the bulk sealer into smaller fragments. In contrast, the self-agglomeration of decomposed nylon fiber might restrain the desirable breakage of the sealer into small fragments.

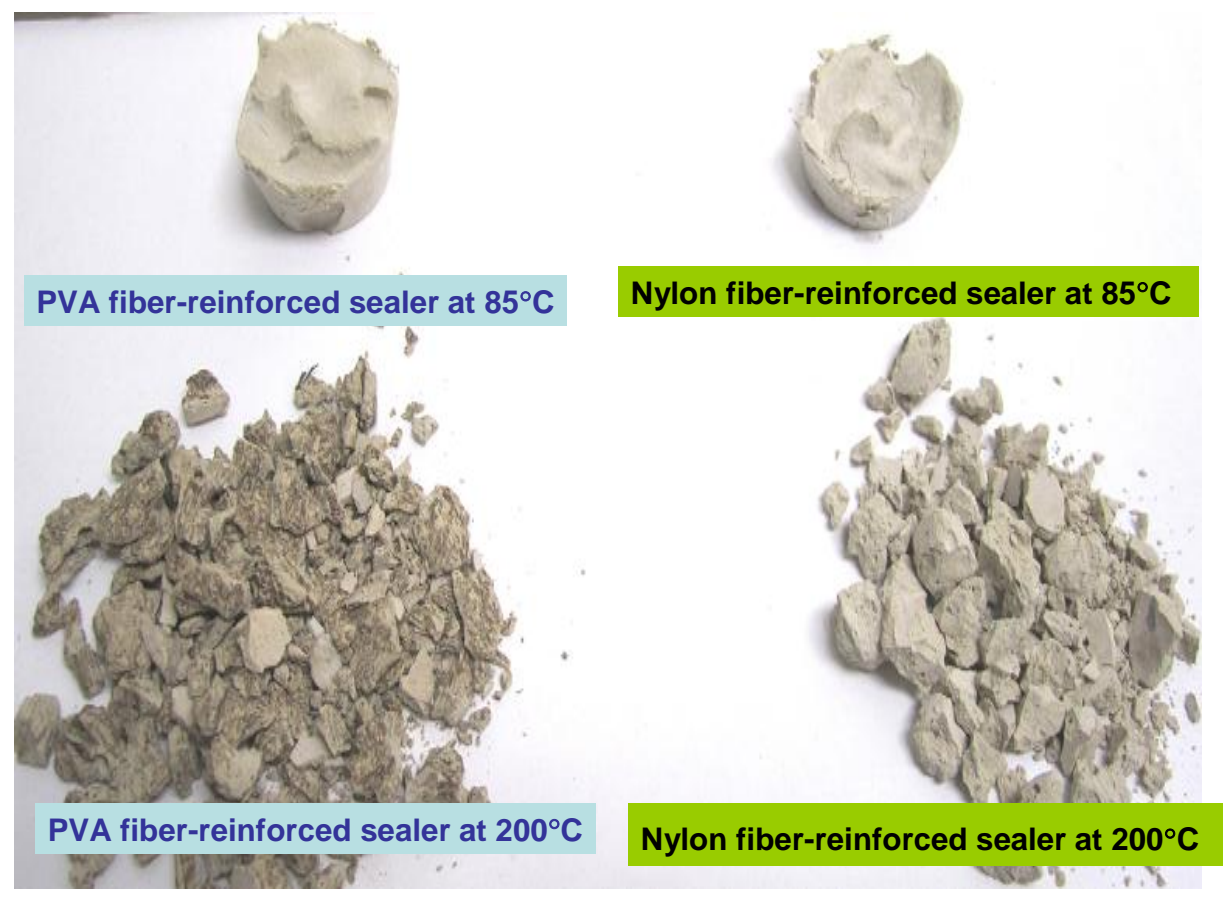

Figure 23. Appearances of PVA-and nylon fiber-bridged sealers after autoclaving for 24 hours at $85^{\circ} \mathrm{C}$ and $200^{\circ} \mathrm{C}$.

To study further the morphological alterations of these fibers developed in the selfdegraded PVA- and nylon-bridged sealers, we explored their microstructure by SEM. For comparison purpose, the $85^{\circ} \mathrm{C}$-autoclaved sealers containing bridging additives also were investigated. Figure 24 shows the SEM images of fracture surfaces for $85^{\circ} \mathrm{C}$-autoclaved PVA fiber-incorporated sealer and $200^{\circ} \mathrm{C}$ treated one. The PVA fibers in the $85^{\circ} \mathrm{C}$ autoclaved sealer remained intact, ensuring that they would aid the sealer in plugging adequately the facture in wells at this temperature. Also, this fracture image revealed an excellent adherence of PVA fiber to SSASC cement because the fiber's surfaces pulled from cement matrix were covered with hydrated cement layer, demonstrating that the failures between fibers and cement matrix occurred in the cement matrix layer as cohesive failure mode. In contrast, there was no evidence of any fibers in the selfdegraded sealer, strongly validating the fact that the PVA fibers were decomposed in the sealer at $200^{\circ} \mathrm{C}$. 


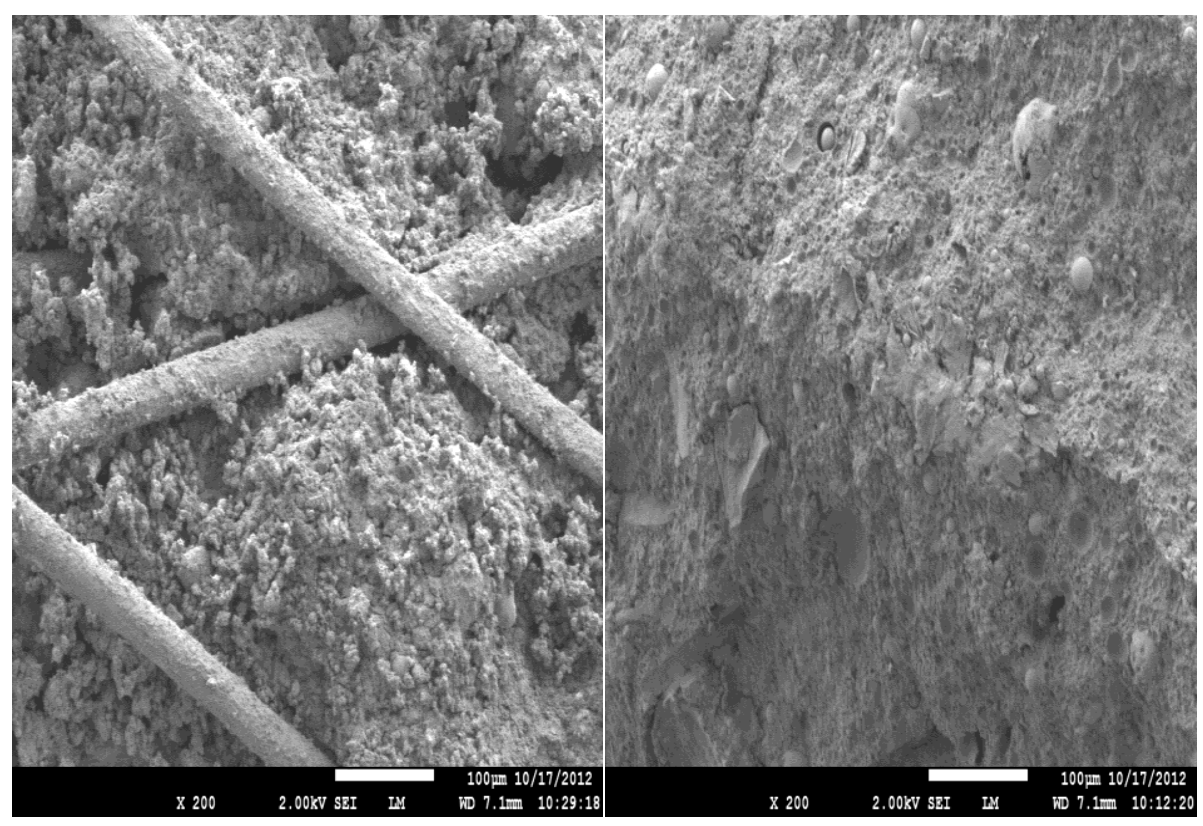

Figure 24. PVA fibers in $85^{\circ} \mathrm{C}$-autoclaved sealer (left) and self-degraded sealer at $200^{\circ} \mathrm{C}$ (right).
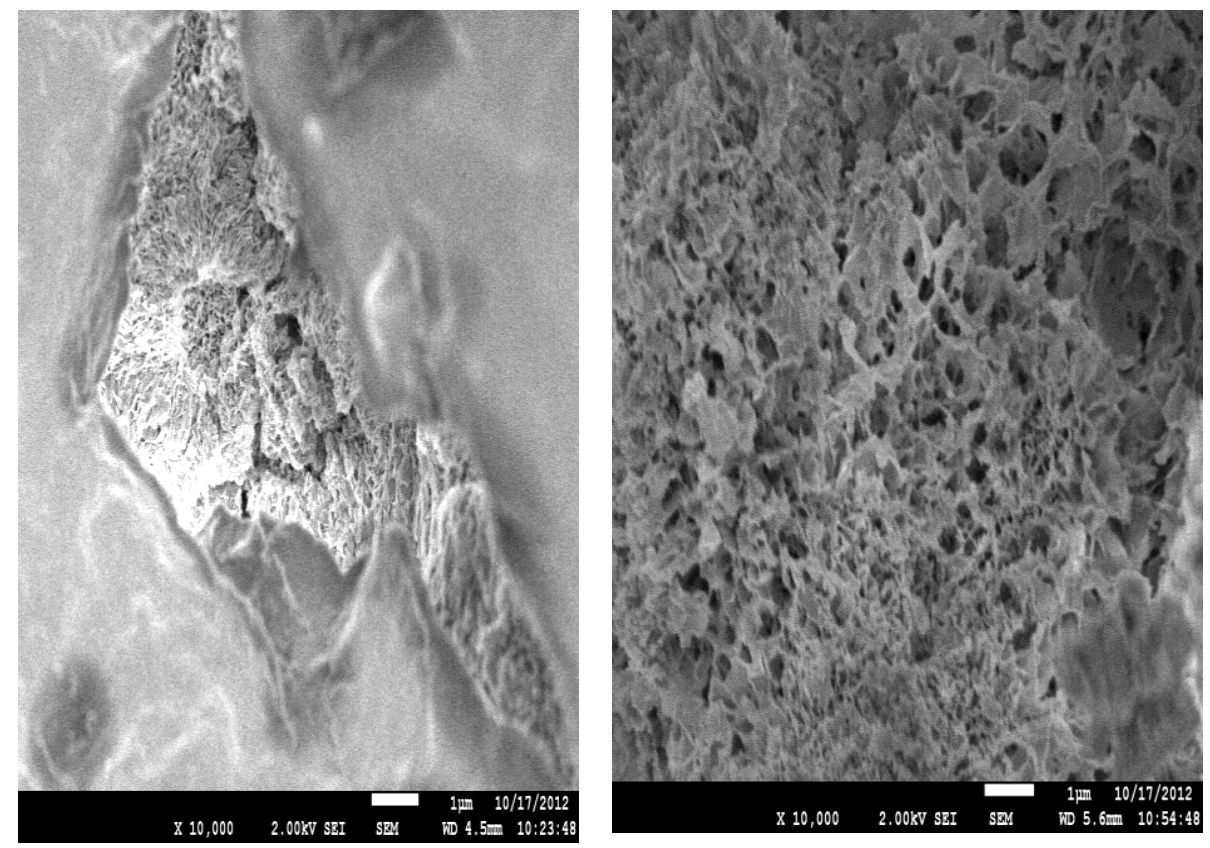

Figure 25. Remnant of self-decomposed PVA fiber in sealer (left) and typical porous microstructure developed in self-degraded sealer matrix (right). 
The morphology of the decomposed fiber differed significantly from the original one and the sealer's micro-structure was very porous with a very large number of voids and craters (Figure 25). The nylon fiber remained intact after the $85^{\circ} \mathrm{C}$-autoclaving (Figure 26). Thus, nylon fiber also appeared to possess the desirable bridging ability to plug the fractures at $85^{\circ} \mathrm{C}$. However, one difference between nylon fiber and the PVA fiber was the fact that the adherence of the former fiber to cement was poor; in fact, when the nylon fibers were pulled out from the cement matrix, the coverage of their surfaces by cement was considerably lower than that of the PVA fibers. No fibers were found in the selfdegraded sealer after $200^{\circ} \mathrm{C}$ exposure but numerous gutters created by the fiber's decomposition.
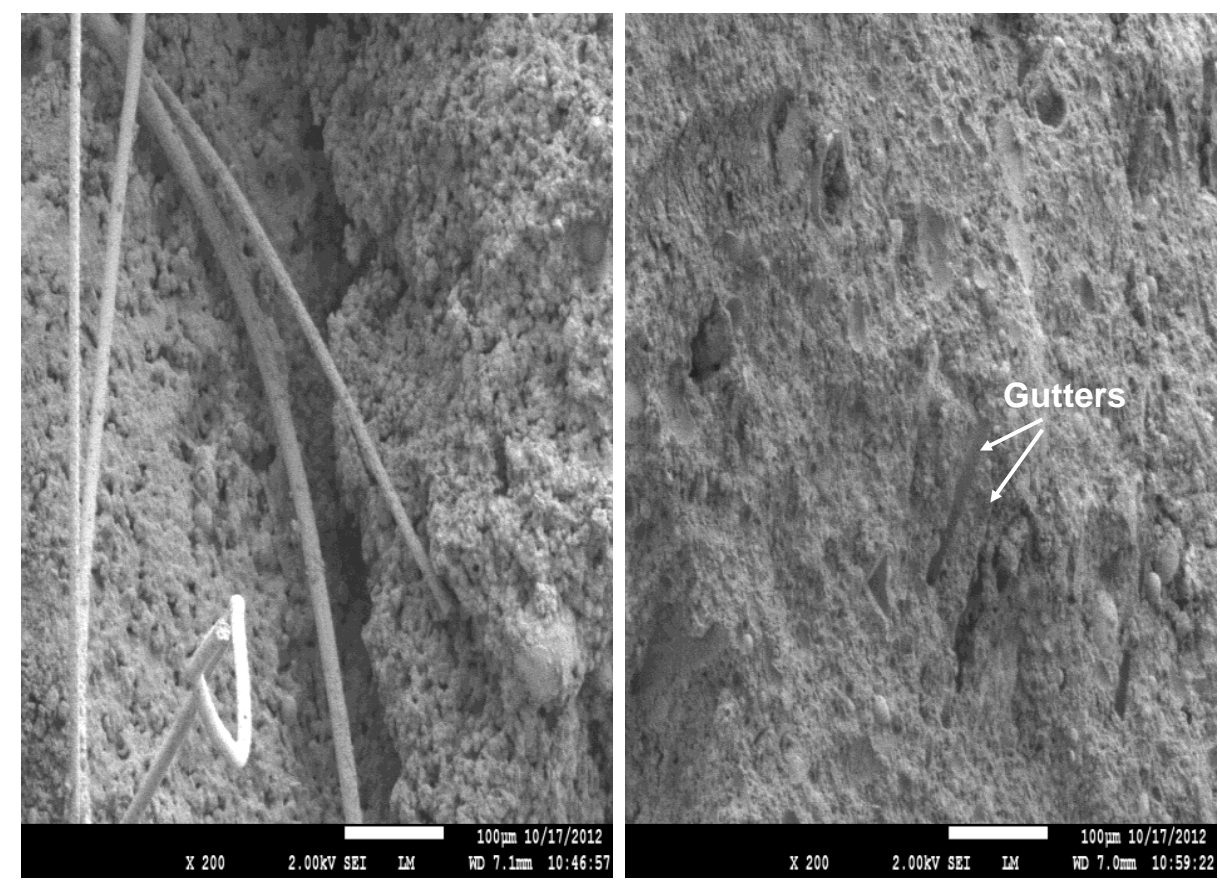

Figure 26. Nylon fibers in $85^{\circ} \mathrm{C}$-autoclaved sealer (left) and self-degraded sealer at $200^{\circ} \mathrm{C}$ (right). 

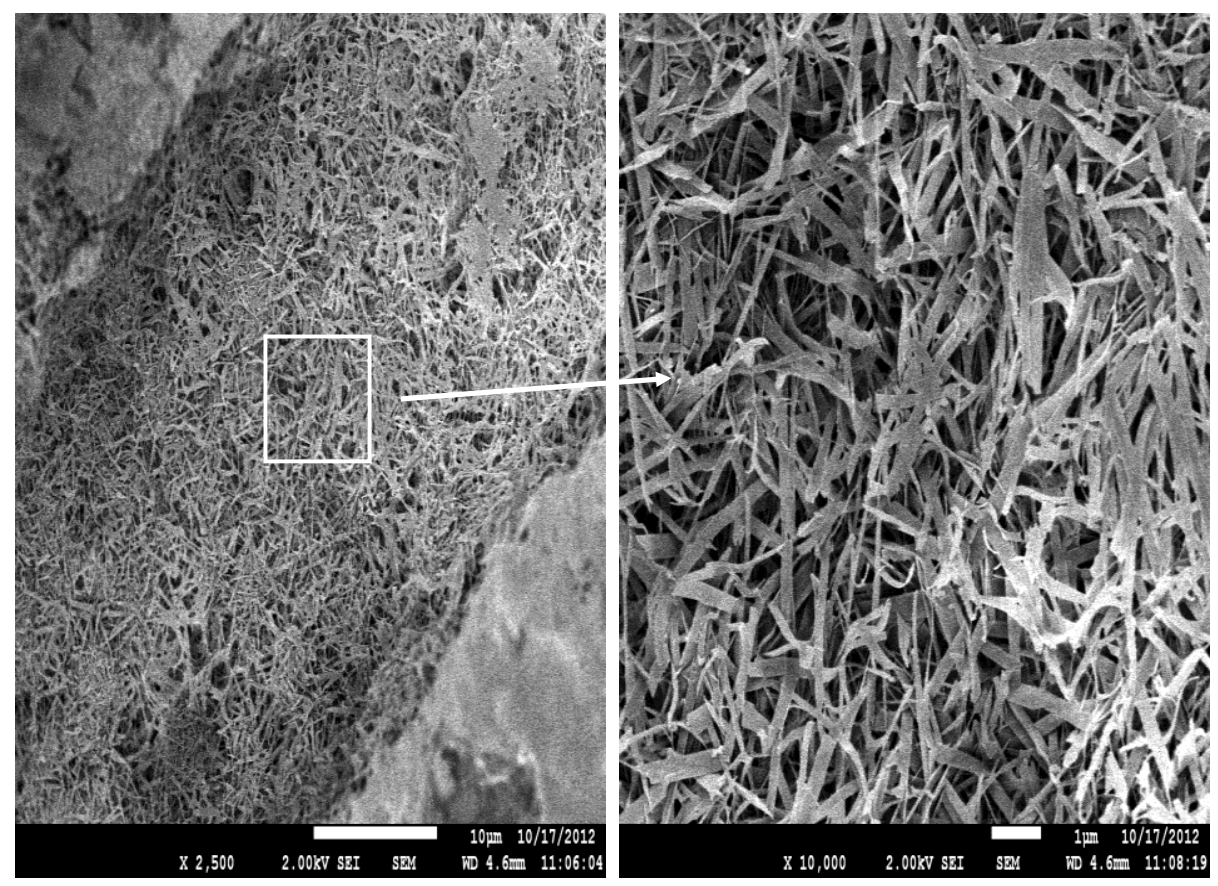

Figure 27. Close-examination for self-degraded nylon-bridging sealer.

Figure 27 reveals the microstructure developed in the gutter. These images demonstrate that the decomposition of nylon fibers in the sealer led to the formation of reticulate network microstructure. Relating this finding to those on the morphological alteration of nylon fiber itself by $\mathrm{pH} 13.7$ pour solution at $200^{\circ} \mathrm{C}$, the agglomerating character of decomposed fiber might be responsible for the fiber $\rightarrow$ reticulate structure transformation in the sealer. Such morphological transformation of nylon fibers impaired decomposition of the sealer into small fragments.

\section{Conclusion}

Using BNL-developed self-degradable cementitious sealer consisting of $20 \mathrm{wt} \%$ slag /80 wt\% Class $\mathrm{C}$ fly ash ratio cement-forming reactants, sodium silicate as alkali activator, and sodium carboxymethyl cellulose as a self-gradation promoter (SSASC cementitious sealer), we addressed the two major issues: Compatibility of the sealer with drilling fluid; Fibrous bridging additives to improve the plugging performance of the sealer in fractures at $85^{\circ} \mathrm{C}$, which would decompose at $200^{\circ} \mathrm{C}$ when the sealer matrix self-degrades. For comparison, the conventional Class $\mathrm{G}$ well cement was used.

In exploring the first issue, SSASC cementitious sealer displayed a great compatibility with drilling fluid; in fact, the maximum heat flowing (MHF) energy generated during sealer hydration remained virtually unchanged after the incorporation of the drilling fluid. Additionally, the MHF value somewhat increased after adding 5 vol. \% drilling fluid, 
compared with that of sealer without drilling fluid. Such increase was due to the alkali activating effect of caustic soda, present in drilling fluid, promoting the hydrolysishydration reactions of slag and Class $\mathrm{C}$ fly ash. The elapsed time of this sealer to reach the MHF did not change markedly with up to $20 \mathrm{vol}$. \% addition of drilling mud. In contrast, the maximum hydration energy significantly decreased and elapsed time significantly increased when drilling fluid was mixed with class $\mathrm{G}$ cement. The compressive strength of the samples autoclaved samples at $85^{\circ} \mathrm{C}$ depended mainly on the MHF energy; namely, samples with lower MHF possessed lower compressive strength. Even SSASC samples with drilling fluid content of 20 vol. \% met the criterion of $\geq 2000$ psi compressive strength, while the Class $\mathrm{G}$ well cement failed to meet this criterion. Further, the compressive strength of SSASC contaminated with drilling fluid depended on the content of sodium silicate activator; namely, more the sealer with higher compressive strength can be prepared by increasing the amount of this activator.

For the second issue, we evaluated the ability of four organic fibers, the acrylic, nylon, polyethylene (PE), and polyvinyl alcohol (PVA), to adequately plug the 1-in. wide x 6-in. long $\mathrm{x} 0.08$ or $0.24 \mathrm{in}$. high slots under pressures of up to $700 \mathrm{psi}$ at $85^{\circ} \mathrm{C}$ and to decompose when the self-degradation of the sealer matrix takes place at $200^{\circ} \mathrm{C}$. Among these fibrous bridging additives, two fibers, PVA and nylon, were identified as the effective ones; ensuring that they aided in improving a plugging performance of the sealer slurry and decomposed when $200^{\circ} \mathrm{C}$-heated fiber-bridged sealer came in contact with water. Also, the length and content of these fibers played an important role in plugging the slots of different sizes. For a $0.08 \mathrm{in}$. high slot, a content of $\geq 1.0 \mathrm{wt} \%$ of these $6 \mathrm{~mm}$-long fibers satisfactorily assured plugging under 700 psi pressure. However, these $6 \mathrm{~mm}$-long fibers were no longer effective in plugging a large size slot of $0.24 \mathrm{in}$. high. The combination of short- and long-fibers was required for adequately plugging such a large size slot. As a result, the four PVA and nylon combined systems, 1) $1.0 \mathrm{wt} \%$ $6 \mathrm{~mm}$-long PVA/0.5 wt\% $19 \mathrm{~mm}$-long PVA, 2) $1.0 \mathrm{wt} \% 6 \mathrm{~mm}$ nylon/0.5 wt\% $19 \mathrm{~mm}$ PVA, 3) $1.0 \mathrm{wt} \% 6 \mathrm{~mm}$ nylon/0.5 wt\% $19 \mathrm{~mm}$ nylon, and 4) $1.0 \mathrm{wt} \% 6 \mathrm{~mm}$ PVA/0.5 wt $\% 19 \mathrm{~mm}$ nylon, adequately plugged $0.24 \mathrm{in}$. high slot. We also investigated the plugging mechanisms of fiber-containing sealer. Under the pressure, the fibers formed a mat-like bridge with the deposition of the sealer slurry at an inlet of the slot nozzle, thereby creating impermeable layers that essentially mitigated the filtration loss of the slurry. Also, such combined fiber systems afforded an improved ductility of the $85^{\circ} \mathrm{C}$ autoclaved sealer. The highest compressive toughness of $3.8 \mathrm{~J} / \mathrm{mm}^{3} \times 10^{3}$ was obtained for the sealer made with $1.0 \mathrm{wt} \% 6 \mathrm{~mm}$ PVA/0.5 wt\% $19 \mathrm{~mm}$ PVA fiber combination; this value was 9.5-fold higher than that of non-bridged sealer. The nylon fibers were not as effective in improving the toughness of the sealer. In fact, when some amount of PVA were replaced by short or long nylon fibers, sealer's compressive toughness was lowered conspicuously, suggesting that PVA fiber had an excellent adherence to the sealer matrix, compared with the nylon fibers.

The ideal self-degrading behavior of fiber-bridged sealer was to convert bulk sealer into small fragments after exposure to $200^{\circ} \mathrm{C}$, followed by contact with water. One important fact governing this behavior was the morphology of by-products derived by alkalicatalyzed decomposition of fiber in sealer with $\mathrm{pH} 13.7$ at $200^{\circ} \mathrm{C}$. The decomposition of 
PVA led to a morphological alteration from a structure of $24 \mu \mathrm{m}$ diam. x $6 \mathrm{~mm}$ long fiber rods to a flake-like fragmental structure with the flake size ranging from $\sim 2 \mu \mathrm{m}$ to $\sim 10$ $\mu \mathrm{m}$. In contrast, the decomposition of nylon fiber resulted in the fiber rods $\rightarrow$ reticulate structure transformation in the sealer. The PVA transformation was responsible for a desirable self-degradation performance with formation of small fragments from the bulk sealer, while the nylon transformation resulted in bigger fragments of the decomposed sealer.

The PVA fiber had a high potential as decomposable bridging or plugging additive for self-degrading temporary SSASC-based sealer at $\geq 200^{\circ} \mathrm{C}$. 


\section{References}

1. T. Sugama, T. Butcher, L. Brothers, and D. Bour, "Self-degradable Cementitious Sealing Materials," October 2010, BNL-94308-2010-IR.

2. T. Sugama, J. Warren, T. Butcher, L. Brothers, and D. Bour, "Self-degradable Slag/Class F Fly Ash-Blend Cements," March 2011, BNL-94911-2011-IR.

3. T. Sugama, T. Butcher, L. Brothers, and D. Bour, "Temporary cementitious sealing materials," GRC Transactions, 35 (2011) 247-253.

4. T. Sugama and T. Pyatina, "Sodium Carboxymethyl Celluloses (CMCs): Selfdegrading Promoters of Temporary Cementitious Sealing Materials," Informal Report submitted to DOE, September 2012.

5. T. Sugama, J. Warren, and T. Butcher, "Adding MgO Improves the Volumetric Expansion of Self-degradable Cements," September 2011, BNL-96339-2011-IR.

6. F. Accion, J. Gobantes, and M. T. Blanco, "Cements reinforced by acrylic fibers, infrared studies. I. Hydration and hydrolysis processes in the fibers," Cement and Concrete Research, 20 (1990) 702-710.

7. V. Mechtcherine, F.de A. Silva, S. Muller, P. Jun, and R.D.T. Filho, "Coupled strain rate and temperature effects on the tensile behavior of strain-hardening cement-based composites (SHCC) with PVA fiber," Cement and Concrete Research, 42 (2012) 1417-1427.

8. G. Daccord, B. Craster, H. Ladva, T. Jones, and G. Manescu (2006) Cementformation interactions. In Well Cementing, 2nd ed. (Nelson E and Guillot D (ed.)). Schlumberger, Sugar Land, USA.

9. E. Santoyo, S. Santoyo-Gutierrez, A. Garcia, G. Espinosa, and S.L. Moya, "Rheological property measurement of drilling fluids used in geothermal wells," Appl. Thermal Eng. 21, (2001) 283-302. 